\title{
Functionalized Graphene Platforms for Anticancer Drug Delivery
}

\section{Shabnam Sattari \\ Mohsen Adeli \\ Siamak Beyranvand \\ Mohammad Nemati}

Department of Chemistry, Faculty of Science, Lorestan University,

Khorramabad, Iran
Correspondence: Mohsen Adeli

Email adeli.m@lu.ac.ir

\begin{abstract}
Two-dimensional nanomaterials are emerging as promising candidates for a wide range of biomedical applications including tissue engineering, biosensing, pathogen incapacitation, wound healing, and gene and drug delivery. Graphene, due to its high surface area, photothermal property, high loading capacity, and efficient cellular uptake, is at the forefront of these materials and plays a key role in this multidisciplinary research field. Poor water dispersibility and low functionality of graphene, however, hamper its hybridization into new nanostructures for future nanomedicine. Functionalization of graphene, either by covalent or non-covalent methods, is the most useful strategy to improve its dispersion in water and functionality as well as processability into new materials and devices. In this review, recent advances in functionalization of graphene derivatives by different (macro)molecules for future biomedical applications are reported and explained. In particular, hydrophilic functionalization of graphene and graphene oxide (GO) to improve their water dispersibility and physicochemical properties is discussed. We have focused on the anticancer drug delivery of polyfunctional graphene sheets.
\end{abstract}

Keywords: two-dimensional nanomaterials, graphene, functionalization, anticancer drug delivery, photothermal therapy

\section{Introduction}

Cancer is a general name for a group of more than 100 diseases and one of the most serious health risks that is the second-leading cause of death worldwide behind cardiovascular disease. ${ }^{1-5}$ Cancer is usually caused by abnormal proliferation of different cells in the body that differ significantly in the complexity of treatment. Abnormal cell proliferation leads to tumor formation that can be benign or malignant. A benign tumor (non-cancerous) is not cancerous and remains confined to its original site and does not metastasize to other regions of the body. However, a malignant tumor (cancerous) is an invasive tumor and spreads through the bloodstream or lymphatic system throughout the body. Benign tumors can usually be removed by surgery, but malignant tumors are often resistant to current treatments and are much more dangerous because of their ability to invade and metastasize to different parts of the body. ${ }^{6,7}$ Many research studies have focused on finding new strategies to reduce the side effects of conventional therapies. ${ }^{8-10}$ Despite its drawbacks and limitations, chemotherapy plays a significant role in cancer treatment. ${ }^{11}$ One of the main challenges associated with chemotherapy is low bioavailability of chemotherapeutic agents and drug-resistant tumor cells. ${ }^{12-14}$ Nanomaterials, due to their unique physicochemical properties, including shape, 
surface, size, and optical properties, are able to target cancerous tissue and cross the biological barriers with minimal side effects. ${ }^{8,15,16}$ Different types of nanomaterials such as organic nanoparticles (polymeric micelles, liposomes, and dendrimers) inorganic nanoparticles (quantum dots, carbon nanotubes, magnetic and metal nanoparticles), 2D nanomaterials (graphene and its derivatives, molybdenum disulfide, boron nitride, black phosphorus nanosheets, transition-metal dichalcogenides, transition metal oxides, metal organic frameworks, layered double hydroxides), nanocomposites, and nanogels have been used for this purpose. ${ }^{17-28}$ To address these problems, anticancer drug delivery systems based on two-dimensional nanomaterials are developed and their ability to target anticancer drugs into tumors is investigated. ${ }^{29}$ Graphene-based nanomaterials due to their excellent physicochemical and biological properties including high loading capacity, photothermal property, and fast cellular uptake have been used to improve current chemotherapies. $^{30-33}$ In this review, we have focused on the functionalized graphene sheets as nanocarriers to transport therapeutic agents into tumors along with a brief discussion on the challenges and future trends in this field.

\section{Graphene Platforms: Structure, Chemistry, and Toxicity}

Graphene is a two-dimensional honeycomb network with $\mathrm{sp}^{2}$ carbon atoms. Each atom is bonded to neighboring carbons by $\sigma$-bond and out of plane p orbitals are extended over the whole structure. Graphene could be considered as the main backbone of various allotropes of carbon including fullerene, zero dimension (0D), nanotubes, one dimension (1D), and graphite, three dimensions (3D) $)^{34}$ (Figure 1). The unique physicochemical, optical, electrical, and mechanical properties of graphene make it a suitable platform for various applications such as energy storage, ${ }^{35,36}$ sensors, ${ }^{37-39}$ biological and medical applications, ${ }^{39-46}$ cancer therapy, ${ }^{47,48}$ functional devices, ${ }^{49-51}$ and drug delivery. ${ }^{52-54}$ High thermal and electrical conductivity, high elasticity and flexibility, and large surface area are some graphene properties superior to other nanomaterials. ${ }^{55,56}$ Due to its outstanding properties
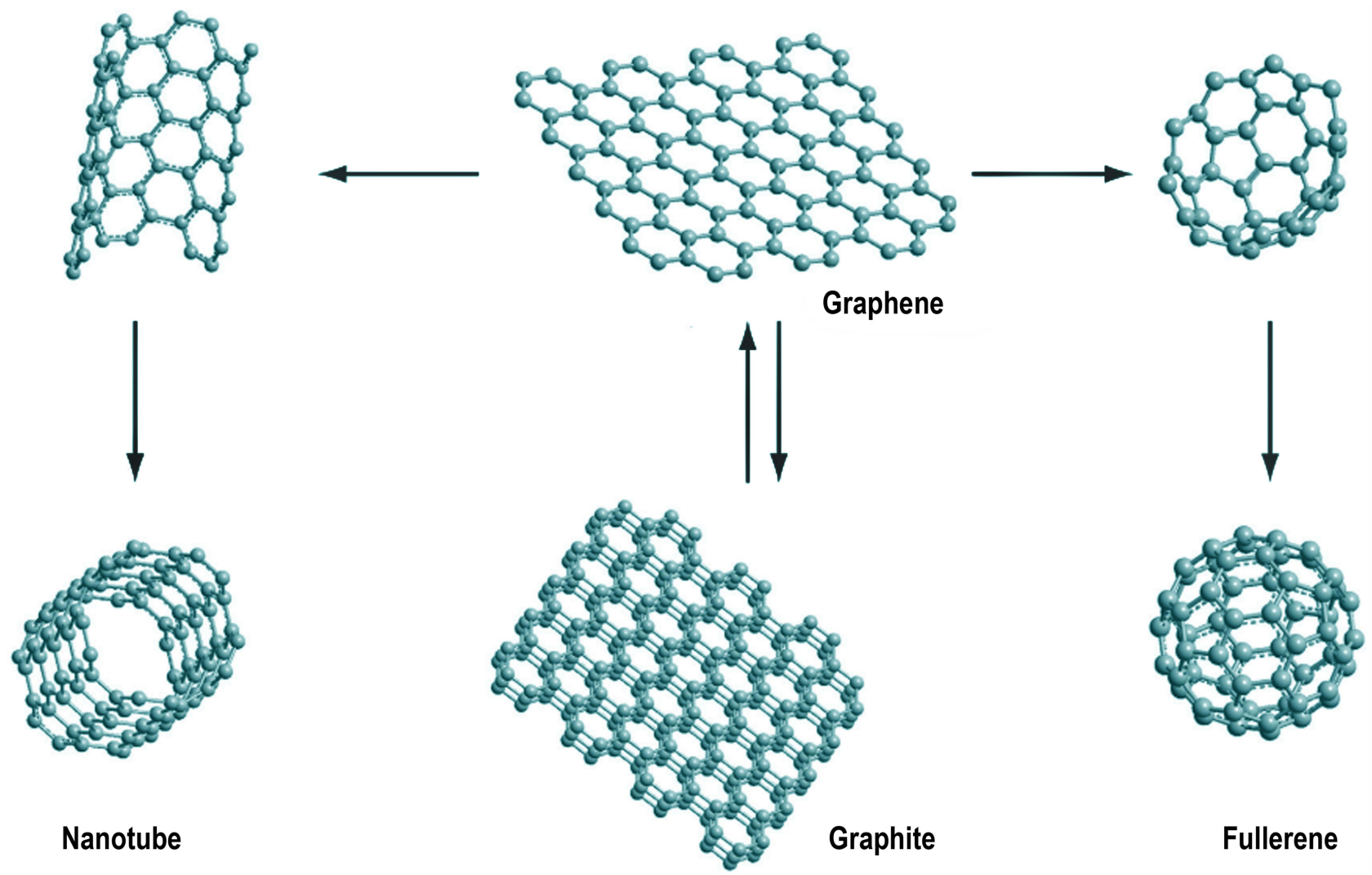

Nanotube

Figure I Graphite and different allotropic forms of carbon.

Notes: Used with permission of Future Medicine Ltd from Tonelli FM, Goulart VA, Gomes KN, et al. Graphene-based nanomaterials: biological and medical applications and toxicity. Nanomedicine. 2015;10:2423-2450; permission conveyed through Copyright Clearance Center, Inc. ${ }^{40}$ 
such as photothermal property, oxidative reactivity, and low price, graphene can be used as an appropriate platform for drug delivery. Also, layer structure of graphene represents a high loading capacity for therapeutic agents. ${ }^{57}$ Despite the extraordinary properties of graphene, one of the main drawbacks of using it for drug delivery is the low dispersibility of this compound in aqueous solutions. Oxidation to graphene oxide (GO), production of reduced graphene oxide ( $\mathrm{rGO}$ ) or functionalization by hydrophilic functional groups are the main strategies to overcome this problem (Figure 2). GO, an oxidized derivative of graphene, consists of a large number of oxygen containing functionalities such as epoxide, hydroxyl, and carboxylic acid. While epoxide and hydroxyl groups are placed in the basal plane, carboxylic groups are placed along the edges. These functional groups improve dispersibility of GO in water. rGO has much less epoxy due to reduction and it shows a low dispersibility in aqueous solutions.

However, one of the main concerns regarding biomedical applications of graphene is the intrinsic toxicity and health risk of this compound. ${ }^{58-61}$ The toxicity of graphene-based nanomaterials mainly depends on different factors including size, surface charge, shape, number of layers, surface functional groups, and particulate state. ${ }^{58,62-64}$ While some studies showed no toxicity and side effects of graphene on mouse cells, others indicated considerable toxicity for graphene. ${ }^{65-67}$ This discrepancy come back to the variation in the structure of graphene derivatives and necessitates more extensive studies to conclude on the toxicity of graphene and its derivatives. Therefore, before any medical applications, a deep understanding of the toxicological profile of graphene-based nanomaterials is required. Cellular studies have shown that graphene and its derivatives can destroy the structures of the cells. For example, graphene caused plasma membrane damage in Hep G2 cells and induced disintegrate the mitochondrial membrane in a dose-time and shape-dependent manner. ${ }^{68,69}$ Moreover, graphene-based nanomaterials led to DNA fragmentation and chromosomal aberrations in human mesenchymal stem cells and cause side effects in normal cells such as immune system cells. ${ }^{70,71}$ Graphene causes apoptosis by inducing mitogen-activated protein kinases and the transforming growth factor- $\beta$-related signaling pathways. ${ }^{72}$ Graphene-based nanomaterials have shown dose-dependent hemolytic activity and aggregated graphene particles have shown considerable toxicity. Some studies have shown that graphene and its derivatives increase intracellular ROS and cause cytotoxicity and induce oxidative stress through which proteins, DNA, and lipid destruction have been damaged. ${ }^{73-77}$

Robert Langer and co-workers played with the functionality of graphene oxide and studied the toxicity effects of different types of graphene oxide on mice. The aim was to find a possible relationship between the amount of oxygen containing functional groups and biocompatibility of graphene oxide. Their results showed that by injecting graphene oxide, this substance becomes a mass in the body. The team found that the mice's body excreted graphene oxide over time.

Researchers have used standard arrays to study the toxicity effects of graphene oxide and have shown that concentrations less than $1 \mathrm{mg} / \mathrm{mL}$ do not show considerable toxicity effects but higher concentrations are toxic to the body. Administration of GO in mice has resulted in chronic toxicity and death from pulmonary granuloma. In addition, dose-dependent pulmonary toxicity, granulomatous lesions, pulmonary edema fibrosis, and inflammatory
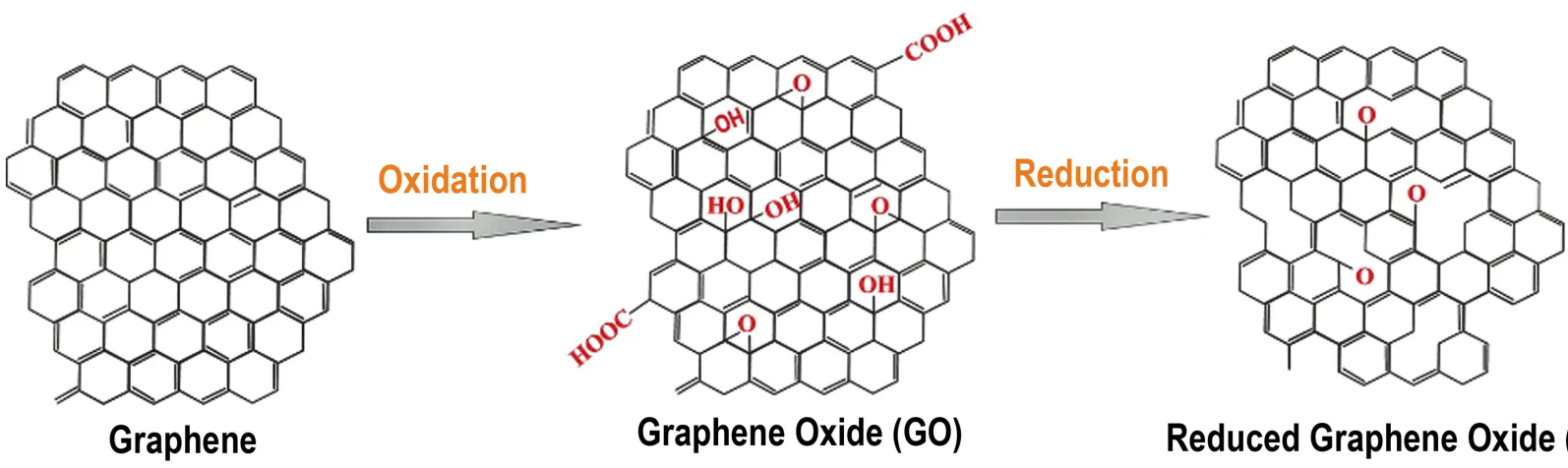

Figure 2 Structure of graphene and its oxidized derivatives.

Notes: Reproduced with permission from Priyadarsini S, Mohanty S, Mukherjee S, Basu S, Mishra M. Graphene and graphene oxide as nanomaterials for medicine and biology application. Journal of Nanostructure in Chemistry. 2018;8:123-137. ${ }^{41}$ Copyright (C) 2018, The Authors. Creative Commons CC BY (https://creativecommons.org/ licenses/by/4.0/legalcode). 
cell infiltration have also been observed after administration of GO. A pulmonary inflammatory response was also observed in rats after administration of graphene with BSA. $^{78-81}$

Functionalization of graphene with different functional groups can potentially improve the bioavailability, circulation lifetime and anticancer property of this material. ${ }^{82,83}$ As previously mentioned, one way to achieve this goal is functionalization of graphene surface by suitable polymers. ${ }^{84}$ Modification of graphene surface by polymers enhances biocompatibility and circulation times of graphene in vivo. PEG is the most studied polymer for the modification and improvement of biological properties of graphene derivatives. Conjugation of PEG onto graphene sheets reduces toxicity and increases stability of graphene under physiological conditions. ${ }^{85,86}$ According to the hematological analysis and histological examinations, nanographene modified PEG do not cause appreciable toxicity at dose $(20 \mathrm{mg} / \mathrm{kg})$ in a period of 3 months. ${ }^{87}$

Pharmacokinetics and clearance of graphene nanomaterials from the body has been studied but it needs extensive investigations to achieve a deep understanding of the long-term toxicity of these materials. ${ }^{88,89}$ The physicochemical properties of graphene derivatives including size, surface charge, surface chemistry, and shape impact their pharmacokinetics dramatically. ${ }^{90}$ Transmission electron microscope (TEM), Raman spectroscopy, isotopic labeling, and rare-earth elements labeling are some of the methods available for tracking these materials in body. ${ }^{87,91-93}$ For example, Liang et al used the $\mathrm{La} / \mathrm{Ce}$ dual elemental labeling method to track the bioaccumulation, transfer, and clearance of polyvinylpyrrolidone (PVP) modified GO in vivo. ${ }^{94}$ They showed that injected PVP/GO mainly accumulate in the lungs, liver, and spleen, then pass through the glomerular filtration barrier (GFB) of the kidney and can be cleared, likely by both renal and fecal excretion. Similar results have been reported for injected PEGylated ${ }^{125}$ I-labeled nanographene sheets. ${ }^{87}$ Injected PEGylated graphene are accumulated in the reticuloendothelial system and gradually cleared from the bloodstream through their sequestration by cells of the mononuclear phagocyte system.

\section{Graphene-Polymer Platforms; Synthesis and Physicochemical Properties}

For many biological applications and in order to improve the functionality and dispersibility of graphene, surface of this nanomaterial should be modified and functionalized. Surface modification of graphene platforms using biocompatible polymers endow new properties and effectively improve their performances for biomedical applications. Taking advantage of the huge conjugated $\pi$-systems, high specific surface area, and useful functionality, graphene platforms can be used as novel nanocarriers for different therapeutic agents. ${ }^{95-98}$ Incorporation of polymeric systems into the graphene structure allows tailoring these platforms into new multifunctional systems to deliver a variety of moieties such as therapeutic, targeting, and diagnostic agents. ${ }^{97,99}$ Non-covalent and covalent functionalization are two major strategies for the modification of graphene and its derivatives. ${ }^{100-106}$

Graphene derivatives can be covalently modified by covalent attachment of polymers through addition of free radicals or dienophiles to their $\mathrm{C}=\mathrm{C}$ bonds. Macromolecules can also be conjugated to GO through silanization, amidation, esterification, and cycloaddition reactions. ${ }^{107,108}$ However, challenges have to be addressed regarding non-destructive and covalent functionalization of graphene derivatives, as the methods previously mentioned cause disruption of $\mathrm{sp}^{2}$ network and electronic and optoelectronic features of these graphene-based platforms. $^{109,110}$ We have previously developed a nondestructive covalent method for the controlled functionalization of nanographene sheets through nitrene [2+1] cycloaddition reaction based on azidodichloro-triazine at ambient conditions. ${ }^{111,112}$ This strategy allows the controlled non-destructive functionalization of graphene with different polymers and (macro)molecules through conjugated triazine groups and opens up new avenues to construct complex devices for future biomedical applications $^{112}$ (Figure 3).

Non-covalent functionalization by supramolecular interactions including, $\pi-\pi$ stacking, hydrogen bonding, and van der Waals force is another strategy for the modification of graphene and its derivatives. While this approach preserved the $\pi$-conjugation and the electronic properties of graphene-based materials, it is unstable and functional groups can be detached upon changes in the environmental conditions. ${ }^{107,108}$

In the past several years, various types of graphenepolymer platforms have been developed and investigated as nanocarriers for therapeutic agents. Poly(ethylene glycol) (PEG), ${ }^{4,113-115}$ polyethylenimine (PEI), ${ }^{116,117}$ chitosan, $^{118,119}$ and hyaluronic acid $(\mathrm{HA})^{120,121}$ are 


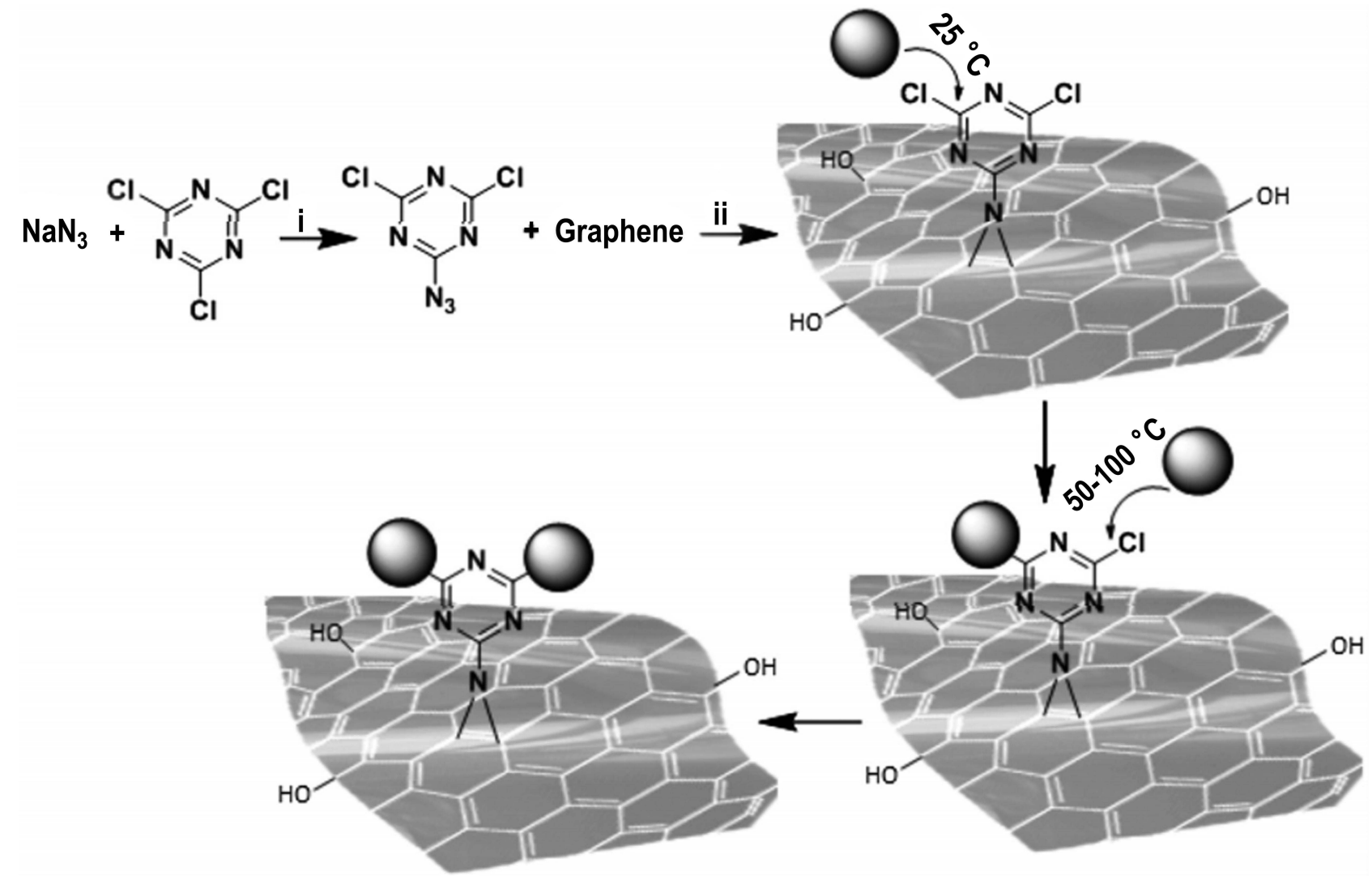

Figure 3 The controlled functionalization of nanographene sheets through nitrene $[2+1]$ cycloaddition reaction at ambient conditions.

Notes: The nucleophilic substitution of chlorine atoms in triazine groups with different polymers and (macro)molecules results in new platforms with defined structures. Reproduced with permission from Gholami MF, Lauster D, Ludwig K, et al. Functionalized graphene as extracellular matrix mimics: toward well-defined 2D nanomaterials for multivalent virus interactions. Adv Funct Mater. 2017;27:1606477. ${ }^{12}$ Copyright 2017, Advanced Functional Materials.

common polymers that are employed for surface functionalization of graphene derivatives. Dendrimers and hyperbranched polymers, including polyamidoamine ${ }^{100,122}$ and polyglycerol $^{9,33,100,123}$ are other types of polymeric systems that are commonly used in this field. Polymers significantly improve the physicochemical properties, solubility, stability, biocompatibility, and drug loading capacity of graphene.

\section{Graphene-Polymer Platforms in Drug Delivery}

Cancer is a major cause of death worldwide and prevention or therapy of this disease is one of the biggest health challenges nowadays. Chemotherapy has been used extensively to treat many types of cancer; however, it is limited by different factors including multidrug resistance, systemic toxicity, immunogenicity, and bioavailability. These limitations could be overcome by drug delivery systems. $^{124-126}$
Among drug delivery systems and breakthroughs, graphene and its derivatives have been abundantly used for a wide range of biomedical applications owing to their sheet-like structure, high specific surface area, and ease of functionalization. ${ }^{99,127,128}$ Due to the availability of different functionalization strategies and taking advantage of the multifunctionality of graphene and its derivatives, various drug delivery systems with controllable biological properties can be prepared. Functionalization of graphene derivatives with various polymers could potentially improve their reactivity, biocompatibility, circulation times in vivo and anticancer capacity. Graphene-polymer platforms with high drug loading capacity have opened up new opportunities in the development of novel drug delivery systems for various biomedical applications, where conventional graphene and polymer alone cannot meet all requirements. ${ }^{32,129-131}$

Functionalization of graphene and its derivatives with PEG have been extensively used for the construction of anticancer drug delivery systems. ${ }^{113}$ Liu et al initially 
reported PEG-decorated GO as a nanocarrier to effectively deliver anticancer drugs. They exploited non-covalent interactions to load anticancer hydrophobic drugs and found that the combination of PEG with graphene-based materials can effectively improve biocompatibility, cellular uptake, bioavailability, physiological stability, therapeutic efficacy, and circulation time of drugs in bloodstream. ${ }^{132}$ On the other hand, PEGylation of graphene reduces aggregates of graphene in RES organs (lungs, liver, spleen, and kidney) as well as its retention and toxicity. Similarly, in another report, 6-armedPEGfunctionalized graphene oxide-based nanocarrier has been reported to deliver anticancer drugs such as oridonin and methotrexate (MTX). ${ }^{133}$ Synthesis of PEG-grafted GO and loading of drugs has been performed via amidation and $\pi$ $\pi$ stacking, respectively. This complex (oridonin or MTX@GO-PEG) exhibited higher cellular uptake and anticancer activity against CAL27 tumor cell in comparison with free drugs. PEGylated graphene has also been developed as dual-drug (DOX and platinum) delivery system with a higher efficiency than the single-drug system. ${ }^{113}$ The results of these studies showed that the combination of drugs efficiently overcomes the cancer drug resistance and improves their anti-cancer effect. This drug delivery system demonstrated less toxicity and damage to normal cells compared to DOX and platinumfree drugs. Interactions of PEGylated graphene with drugs have been adjustable by polymer chain length. ${ }^{134,135}$ In another study, PEGylation of GO using PEG copolymer conjugated to multiple pyrenes increased percentage of PEG on GO surface and simultaneously reduce GO to rGO. In-vitro assays of this study revealed that graphene with PEG content higher than $75 \%$ and longer PEG chain showed better physicochemical properties than their analogs with shorter PEG chains. ${ }^{134}$ The combination of PEG with other polymers such as hyaluronic acid, polyethyleneimine, and chitosan have also been intensively investigated in order to improve therapeutic effects of graphene-drug platforms. ${ }^{34-38,136}$

PEI a cationic polymer is another type of widely explored polymers for the surface modification of graphene-based materials. ${ }^{116,137,138}$ It was found that bare PEI with high molecular weight induced high cytotoxicity due to high cellular uptake and low biodegradability, while its hybridization with carbon materials resulted in a low cytotoxicity. Commonly, PEI is able to form a complex with graphene derivatives via electrostatic interactions and amination methods. PEI-graphene are cationic platforms with multiple advantages including high hydrophilicity, biocompatibility, strong binding to nucleic acids, effective cell uptake, and thermal stability. We report that co-delivery of therapeutic genes and chemotherapy downregulates tumor cell resistance to anticancer drugs and overcome multidrug resistance (MDR). ${ }^{139,140}$ PEI-conjugated graphene has been developed for co-delivery of DOX drug and p53 tumor suppressor gene in order to inhibit HeLa cell growth. Owing to presence of PEI cationic polymer and synergistic effect of drug and gene, DOX/GO-PEI/p53 complex has been efficiently internalized into HeLa cells via endocytosis and has exhibited higher growth inhibition than the single drug/gene delivery system. ${ }^{141}$ In 2019 , Mallick et al developed an interesting polymer-graphene platform based on self-assembled PEI covered graphene oxide nanoparticle (PEI-GTC-NP) for codelivery of cisplatin and topotecan into mitochondria. This platform is able to target drugs into mitochondria of cancer cells effectively. Reactive oxygen species (ROS) were generated at specific sites in mitochondria, which in turn led to apoptosis of cancer cells (Figure 4). ${ }^{116}$ Topotecan have been loaded on GO by $\pi-\pi$ stacking to visualize nanomaterial in cancer cell's mitochondria by fluorescence emission. Cisplatin was also applied as chemotherapy medication to treat cervical cancer. Localization of PEIGTC-NPs into cancer cell resulted in mitochondrial membrane perforation. MTT assay indicated that the half maximal inhibitory concentration $\left(\mathrm{IC}_{50}\right)$ for nanoparticles in the absence of PEI (GTC-NPs) is higher than PEI-GTCNPs. This nanoparticle with positive surface charge and suitable size has been able to penetrate into mitochondria of cancer cells specifically and has shown good potential for treatment of cancer.

Natural biopolymers owing to their low toxicity, biodegradability, renewability, environmental sensitivity, and biocompatibility are also promising materials to improve the biological properties of graphene-based materials. ${ }^{142-145}$ Chitosan with anticancer activity and as a $\mathrm{pH}$ sensitive polymer has been widely employed in the synthesis of polymergraphene hybrids. ${ }^{146-148}$ The produced multifunctional scaffolds have exhibited high loading capacities and functional binding sites for different types of drugs and targeting ligands. ${ }^{147-149}$ Moreover, graphene-chitosan platforms have been widely studied as a $\mathrm{pH}$-sensitive nanovehicle for the targeted release of drugs into cancer cells. Graphene oxidechitosan hybrids have been developed by Dhanavel and coworkers for the controlled delivery of 5-Fluorouracil (5-FU) and curcumin (CUR). These systems have been synthesized 


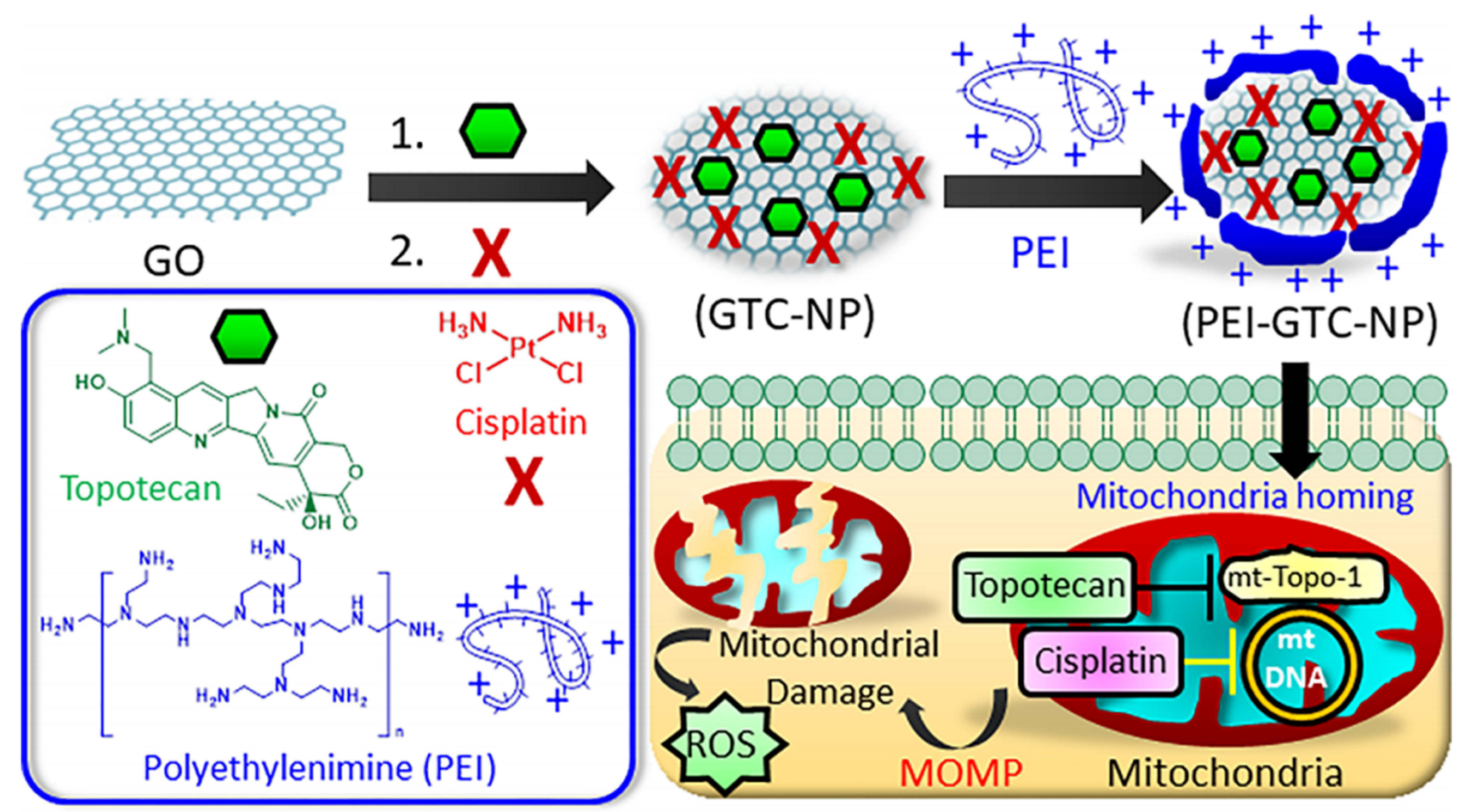

Figure 4 GO with PEl coverage coloaded with cisplatin and topotecan for mitochondria targeting of cancer cells.

Notes: Reproduced with permission from Mallick A, Nandi A, Basu S. Polyethylenimine coated graphene oxide nanoparticles for targeting mitochondria in cancer cells. ACS Applied Bio Mater. 2018;2:14-19. ${ }^{16}$ Copyright 2019, American Chemical Society.

by conjugation of chitosan to GO nanosheet through tripolyphosphate as a crosslinker. Chitosan/reduced graphene oxide (CS/rGO) has displayed $\mathrm{pH}$-dependent drug release behavior. In 2018, Zhao et al reported a chitosan-graphene drug delivery system. It was a core-shell structure containing graphene oxide nanoparticles (GONs) as core and chitosan as surface charge-reversible shells, which was deposited on graphene core via self-assembly (Figure 5). ${ }^{150}$ Doxorubicin (DOX) via the non-covalent interactions ( $\pi-\pi$ stacking) bound to the large $\pi$ conjugated system of GO and chitosan shells prevents premature secretion of loaded DOX in the medium. Due to the lower $\mathrm{pH}$ in cancerous tissue, the coated chitosan was separated, thus accelerating the release of DOX. The charge of these nanomaterials changes from negative at $\mathrm{pH}=7.4$ in the bloodstream to positive at $\mathrm{pH} 6.5$ in the tumor tissue. Chitosan-graphene platform showed advantages over the usual drug delivery systems including high drug loading capacity (DL), great encapsulation efficiency (EE), long-time circulation in bloodstream, improved cellular uptake, and adjustable controlled release of anticancer therapeutics.

While CS has been widely explored in biomedical and environmental fields, there have been some limitations including insolubility at neutral $\mathrm{pH}$ and low rate of degradation. ${ }^{148}$ These problems have been overcome by combining CS with other biopolymers such as cellulose, dextrin, sodium alginate, and so on. ${ }^{151-154}$ Multilayers of biopolymers can be disposed of on graphene through various techniques. ${ }^{155,156}$ In a study, layer-by-layer (LbL) self-assembly technique has been explored for deposition of CS and dextrin on graphene surface. ${ }^{157}$ In this process GO has been first modified with CS, followed by conjugation of dextrin (Dex) via electrostatic interaction with oppositely charged polyelectronic. The GO-CS/Dex conjugate has shown high drug loading capacity, physiological stability, and cellular uptake, compared with GO-CS. In another study, CS has been modified by poly(itaconic acid-copolymerized acrylic acid) in order to increase hydrophilic nature of chitosan. ${ }^{53}$ This new combination has been used for the modification of GO-amine (AGO) with anticancer drug delivery application. CS-GO hybrid has been prepared via electrostatic interactions between chemically modified chitosan as an anionic polyelectrolyte and AGO which acts as a cationic polyelectrolyte. ${ }^{118}$ Omidi et al, ${ }^{119}$ Samadi et al, ${ }^{158}$ and Lei et $\mathrm{al}^{159}$ have also verified improvement of physicochemical and biological properties of graphene-chitosan composites through integration with other polymers.

HA is recognized as another important polysaccharide for the improvement of the biological properties of graphene- 


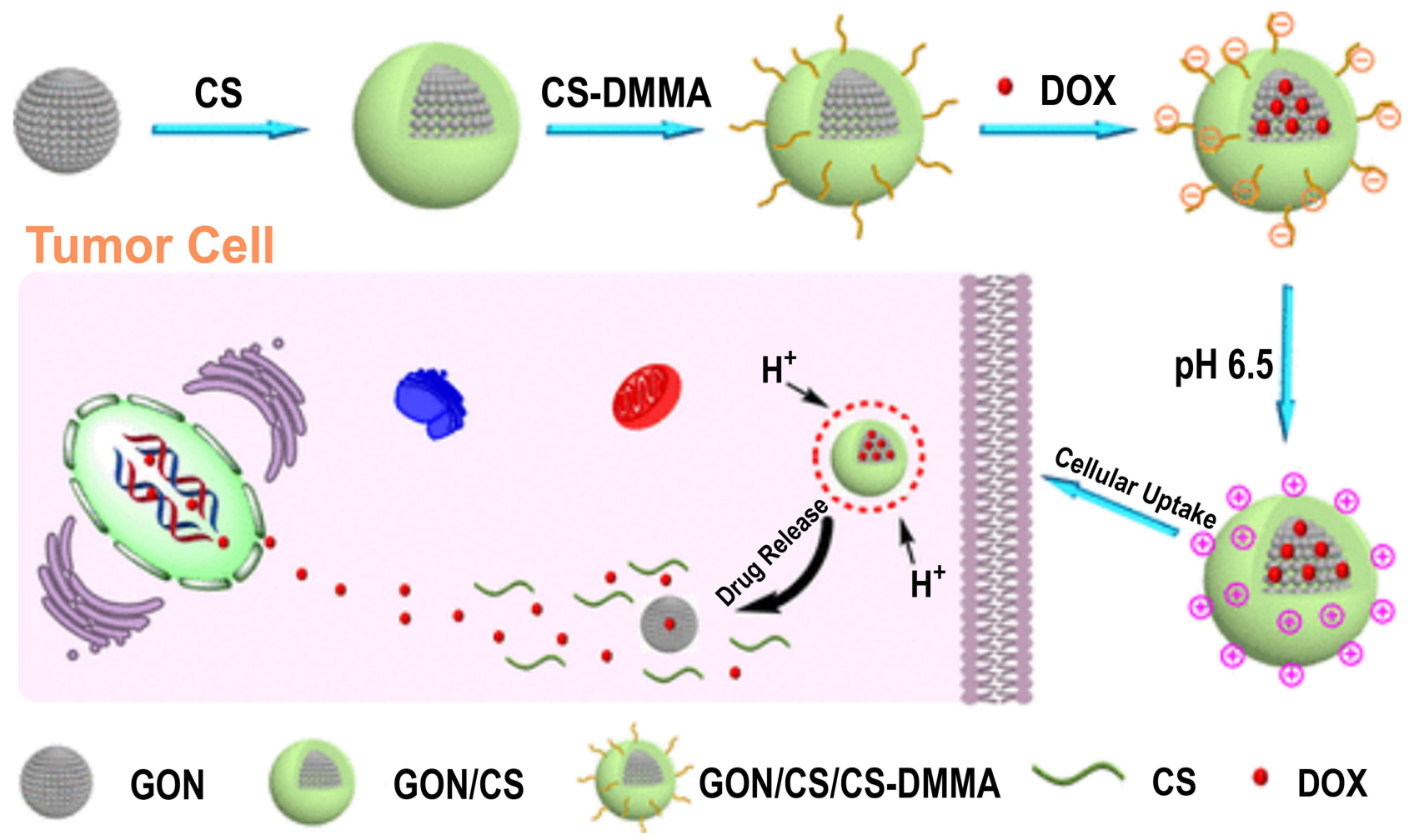

Figure $\mathbf{5}$ Schematic representation of the synthesis and cellular uptake of GO nanoparticle/chitosan hybrids as drug delivery system.

Notes: This system was sensitive to changes in $\mathrm{pH}$ through which intracellular DOX delivery was controlled. Reproduced with permission from Zhao X, Wei Z, Zhao Z, et al. Design and development of graphene oxide nanoparticle/chitosan hybrids showing $\mathrm{pH}$-sensitive surface charge-reversible ability for efficient intracellular doxorubicin delivery. ACS Appl Mater Interfaces. 2018;10:6608-6617. ${ }^{150}$ Copyright 2018. American Chemical Society.

based materials. $^{121,160,161}$ Biomedical applications of HA and its usage for the production of anticancer drug delivery systems have been widely developed, due to its excellent biocompatibility, biodegradability, as well as strong binding affinity and selective targeting of tumor markers, especially the cluster determinant 44 (CD44) and hyaluronan receptor (HARE). ${ }^{162-164}$ Yin's group has prepared redox-sensitive hyaluronic acid-graphene oxide (HSG) composite and studied its ability to target HA-receptor overexpressing tumors and efficiency of redox-sensitive linkages to localize drugs at the target sites. This system was synthesized by conjugation of hyaluronic acid to GO nanosheet using disulfide linkages (HSG). HSG-DOX displayed accelerated release of DOX in acidic environments. Because high activity of hyaluronidase (HAase) in acidic conditions resulted in degradation of hyaluronic acid chains into small pieces and promoted release of DOX. Owing to high drug-loading capacity, photothermally controlled effects, specific targeting of HA receptors overexpressing tumors, and redox-dependent response, HSGDOX showed amplified chemotherapeutic outcomes. ${ }^{161}$

Dendrimers and hyperbranched polymers, especially polyglycerol, are able to effectively improve biological properties and biofunctionality of graphene sheets, as demonstrated in our previous studies. ${ }^{51,100,103,112,131,165-167}$ Our group implemented a new method for functionalization of graphene-based nanomaterials with hyperbranched polyglycerol. ${ }^{14}$ Thermally reduced GO was functionalized by triazine and consequently conjugated with hyperbranched polyglycerol through triazine functional groups. The polyglycerol-covered nanographene with mitochondria-targeted ligands and $\mathrm{pH}$-triggered surface charges showed a high loading capacity and triggered release of DOX drug in the acidic environment (Figure 6). Owing to photothermal properties of nanographene, this multifunctional drug delivery system exhibited accelerated drug release and enhanced chemotherapeutic effect after NIR irradiation. The authors concluded that the high accumulation of smart multifunctional drug delivery system in mitochondria and nucleus, together with photothermal properties, were the reasons for the enhanced chemotherapeutic effects. ${ }^{14}$

\section{Targeted Drug Delivery}

One of the cancer treatment methods that has received a great deal of attention is targeted delivery in which anticancer drugs are transported to the target tissues specifically. 


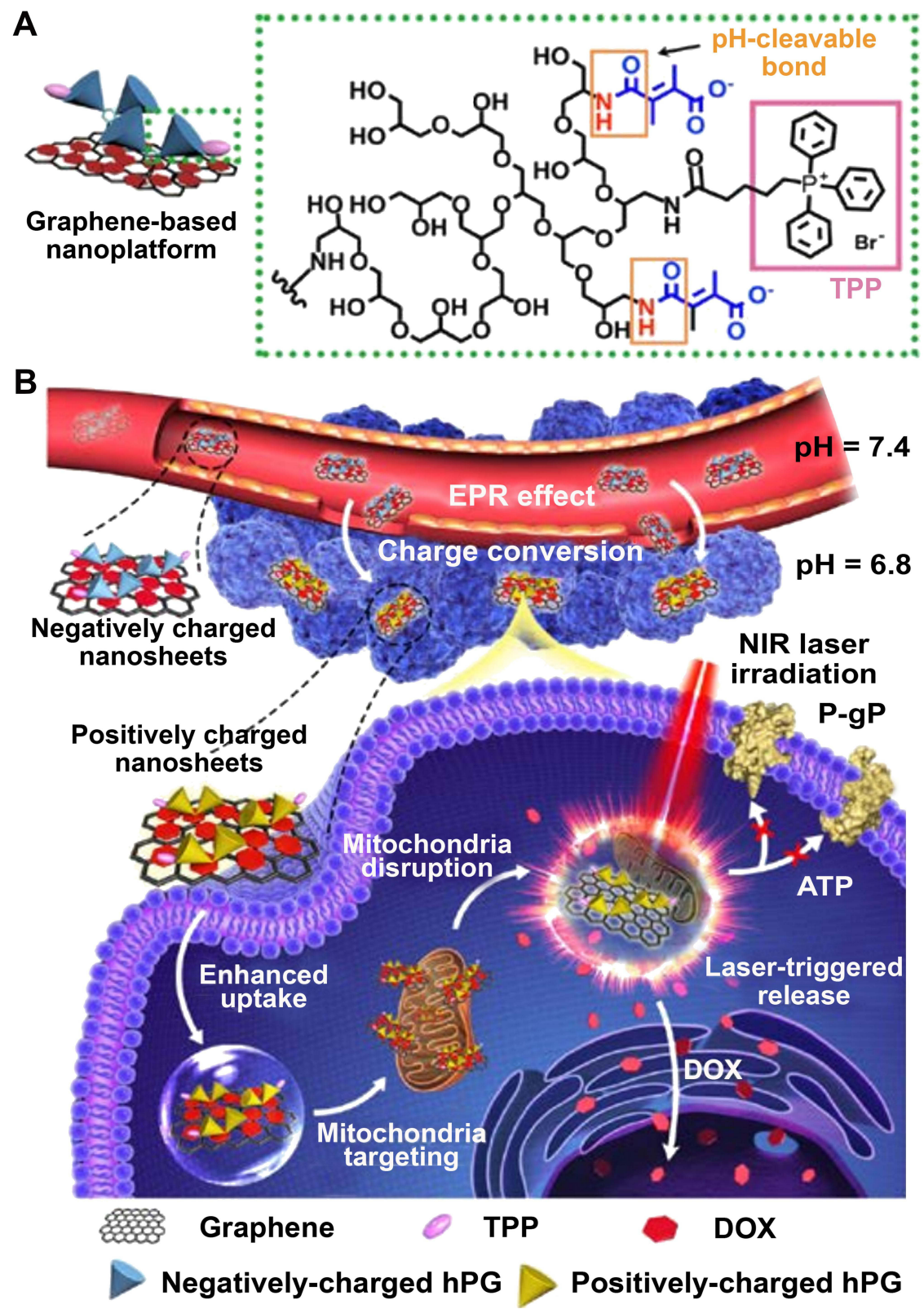

Figure 6 (A) The chemical structure of the polyglycerol-covered nanographene with the mitochondria-targeting ligands and charge conversional functional groups. (B) Multifunctional drug delivery system accumulates in mitochondria by targeting ligands and photothermal properties under NIR laser irradiation result in drug release and good therapeutic efficiency.

Notes: Reproduced with permission from Tu Z, Qiao H, Yan Y, et al. Directed Graphene-based Nanoplatforms for hyperthermia: Overcoming multiple drug resistance. Angewandte Chemie. 2018;130:1 1368-11372. ${ }^{14}$ Copyright (C) 2018 Wiley-VCH Verlag GmbH \& Co. KGaA, Weinheim.

The method is designed by attaching targeting agents to nanocarriers. Targeting drug delivery systems increases the localization of drugs at tumor sites and diminishes the side effects of chemotherapies. Accordingly, a drug delivery system with targeting ligands and good emission property in visible and infrared has been prepared by loading anticancer drugs onto NGO. ${ }^{168}$ Zhang et al have developed GO as a drug delivery system by loading DOX and Camptothecin (CPT) on its surface and conjugation of folic acid to transport cargos to the tumor sites. FA-conjugated NGO (FA-NGO) was able to target MCF-7 cells, and human breast cancer cells by interaction with FA receptors. ${ }^{68}$ Some superparamagnetic nanocarrier based on attaching $\mathrm{Fe}_{3} \mathrm{O}_{4}$ as a magnetic nanocarrier on $\mathrm{GO}$ and aptamer (APT) as a targeting moiety for MCF-7 cancer cell is prepared and then, paclitaxel (PAC) is loaded as an anti-cancer drug. This system has shown advantages including biocompatibility, pH-responsivity, thermal stability, and high drug 
loading capacity over similar nanocarriers. ${ }^{169}$ A rGO-based system with the ability to deliver DOX to human breast adenocarcinoma cancer cells (MDA-MB-231) is also reported. In this system, a thiol maleimide containing catechol (dopa-MAL) is assembled on the surface of rGO by $\pi-\pi$ stacking. Then, a cancer cell targeting cyclic peptide is attached to dopa-MAL. This nanostructure has shown a high efficiency against MDA-MB-231 cells with an IC50 $=58 \mu \mathrm{g} \mathrm{mL}^{-1}$ for DOX-loaded rGO/dopa-MAL-c (RGDfC), corresponding to an IC50 $=9.9 \mu \mathrm{g} \mathrm{mL}-1$ for DOX in the matrix (Figure 7). ${ }^{170}$

Hyaluronic acid (HA) is also used to target GO into cancer cells. GO with HA functionality (GO-HA) has been coloaded with DOX and paclitaxel (Ptx) and the obtained drug delivery system (GO-HA-DOX/Ptx) has been used for the efficient incapacitation of cancer cells. ${ }^{170}$

Another target drug delivery system is designed based on dopamine (DA) functionalized nGO nanocarrier (DAnGO). DA improves the delivery of methotrexate (MTX) as an anticancer cargo into target cells. ${ }^{171}$ Song et al have produced a targeted drug delivery system by loading $\mathrm{Fe}_{3} \mathrm{O}_{4}$ nanoparticle on the surface of $\mathrm{GO}$ and conjugation of lactoferrin (Lf) as a targeting ligand to this platform. The results have shown that this system (Lf@GO@ $\mathrm{Fe}_{3} \mathrm{O}_{4} @ \mathrm{DOX}$ ) has the ability to deliver drugs into C6 glioma cells effectively. ${ }^{172}$

Conjugation of polymers and targeting ligands onto the surface of graphene derivatives improves the therapeutic efficiency of these platforms by increasing their loading capacity and decreasing their side effect as well as efficient localization of drug delivery systems in the targeted cells (Figure 8). ${ }^{173}$

\section{Smart Platforms}

To overcome the limitations of conventional drug delivery systems such as poor tumor penetration, collateral damage to healthy tissues and uncontrollable drug release, stimuliresponsive drug delivery systems, in which therapeutic agents can be activated by endogenous or exogenous stimuli, have been developed. ${ }^{174,175}$ Graphene-based platforms can be excellent candidates in this regard, since they are sensitive to changes in tumor microenvironment/intracellular signals and response to physical stimuli factors. ${ }^{175-179}$

Due to the conversion of glucose to lactose, cancerous tissues are more acidic ( $\mathrm{pH}$ 6.5-7.2) than both blood and healthy tissues $(\mathrm{pH}$ 7.4). Therefore, conjugation of $\mathrm{pH}-$ responsive ligands to the platforms results in controlled drug release at tumor sites. ${ }^{180-182}$ Accordingly, graphenepolymer platforms with $\mathrm{pH}$ sensitive functional groups $\left(\mathrm{COOH},-\mathrm{NH}_{2}\right.$, and $\left.-\mathrm{SO}_{3} \mathrm{H}\right)$ have been widely explored to control the release of various therapeutic agents at tumor sites. An example of such systems has been recently reported by our group. ${ }^{14}$ Graphene-based drug delivery systems with charge conversional property was synthesized through functionalizing polyglycerol-covered nanographene sheets with 2,3-dimethylmaleic anhydride (GPTD) (Figure 6). The surface charge of this system

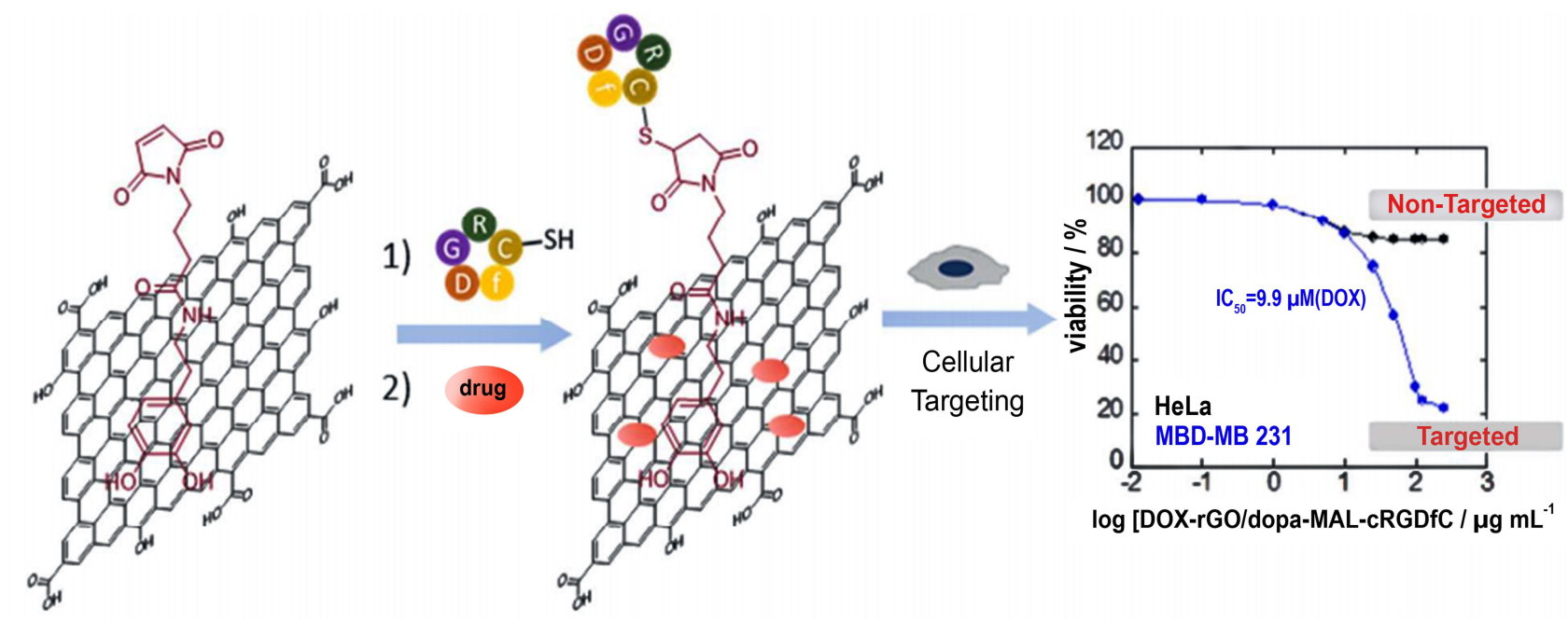

Figure 7 Functionalized rGO with thiol-maleimide containing catechol (dopa-MAL) as a targeted drug delivery system for DOX to destroy human breast adenocarcinoma cancer cells (MDA-MB-23I).

Notes: Reproduced with permission from Oz Y, Barras A, Sanyal R, Boukherroub R, Szunerits S, Sanyal A. Functionalization of reduced graphene oxide via thiol-maleimide "click" chemistry: facile fabrication of targeted drug delivery vehicles. ACS Appl Mater Interfaces. 2017;9:34194-34203. ${ }^{170}$ Copyright @ 2017, American Chemical Society. 

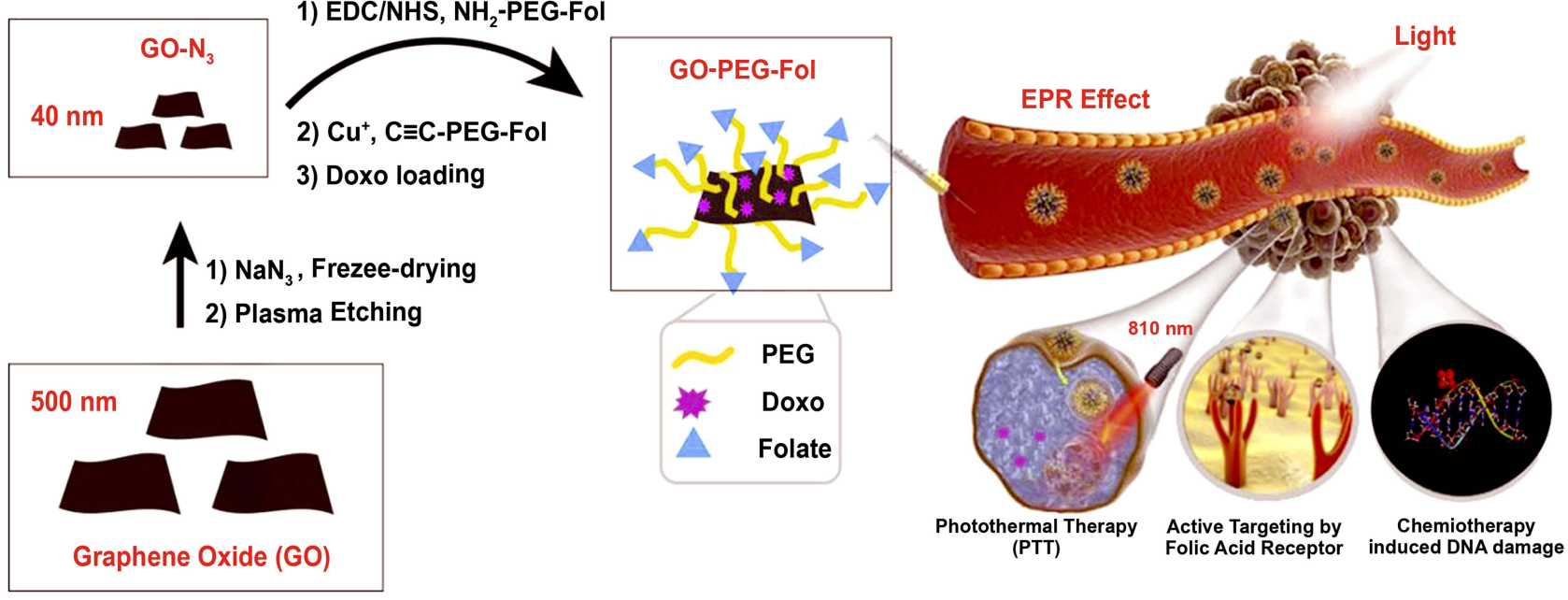

Figure 8 Synthesis of folic acid-functionalized PEGylated GO (GO-PEG-Fol), with small size and narrow size distribution ( $\sim 30 \pm 5 \mathrm{~nm})$, and the ability of efficient converting NIR light into heat.

Notes: GO-PEG-Fol is able to actively target MCF7 and MDA-MB-23I cells. Reprinted from Materials Science and Engineering: C, Vol 107, Mauro N, Scialabba C, Agnello S, Cavallaro G, Giammona G, Folic acid-functionalized graphene oxide nanosheets via plasma etching as a platform to combine NIR anticancer phototherapy and targeted drug delivery, Pages No., I 1020 I Copyright (2020), with permission from Elsevier. ${ }^{173}$

changed from negative at $\mathrm{pH} 7.4$ to positive at $\mathrm{pH} 6.8$. Therefore, it was negatively and positively charged in the blood stream and tumor tissue, respectively. These unique features resulted in a longer-term circulation and increased permeability and retention (EPR) effect of drug delivery systems in body and better localization and controlled release of payloads at tumor sites. This multifunctional drug delivery system showed significant synergistic hyperthermia and chemotherapy effects and showed a high potential in multidrug resistance chemotherapy. ${ }^{14}$

Charge conversional graphene platforms are promising nanocarriers for site-specific delivery of drug because of their charge conversion at reduced $\mathrm{pH} .^{183-185}$ Our group reported a charge conversional graphene platform to promote cellular uptake of loaded drugs ${ }^{166}$ (Figure 9). In this work, polyglycerol containing sulfate and amino groups were conjugated to GO surface, yielding charge-conversional systems. The protonation of $\mathrm{hPG}$ amine in the acidic environment accelerated the release of DOX due to repulsion between protonated DOX and hPG amine. On the other hand, due to weakening $\pi-\pi$ stacking and hydrophobic interactions between the graphene-polymer platforms and doxorubicin, as well as increasing solubility of drug in acidic conditions, effective release of drug occurred in this condition. $^{166}$

It is known that antioxidant concentration (such as GSH) in intracellular microenvironment of tumor tissues $(1-10 \mathrm{mM})$ is often higher than that in normal tissues $(20$
$-40 \mu \mathrm{M}) .^{186,187}$ This feature is important in the development of graphene-based smart systems. Internalized graphene-based platforms with disulfide bonds and redox properties are able to deliver drugs and release them at tumor sites efficiently. DOX has been linked to PEG/PCL copolymer via disulfide bonds and then decorated on graphene surface through hydrophobic interactions. The release of drugs from this system was controlled by redox factors such as GSH. ${ }^{188}$

Apart from their ability to provide intracellular responsiveness, graphene platforms also have the capability to respond to some exogenous stimuli ${ }^{189}$ including light and magnetic fields, which will be discussed later.

\section{Graphene-Polymer Platforms in Bioimaging}

Bioimaging techniques have a broad range of biomedical applications, from diagnosing diseases to investigating body tissues at the cellular level. ${ }^{190}$ Previously, these techniques were mostly used in orthopedic diagnosis. Upon development of imaging tools and methods, other techniques such as magnetic resonance imaging (MRI), X-ray computed tomography (X-ray $\mathrm{CT}$ ), ultrasound, radio wave technology etc. were also used in various medical fields. ${ }^{191,192}$ Bioimaging by both optical microscopy such as laser scanning confocal microscopy (LSCM) and electron microscopy such as liquid cell electron microscopy 


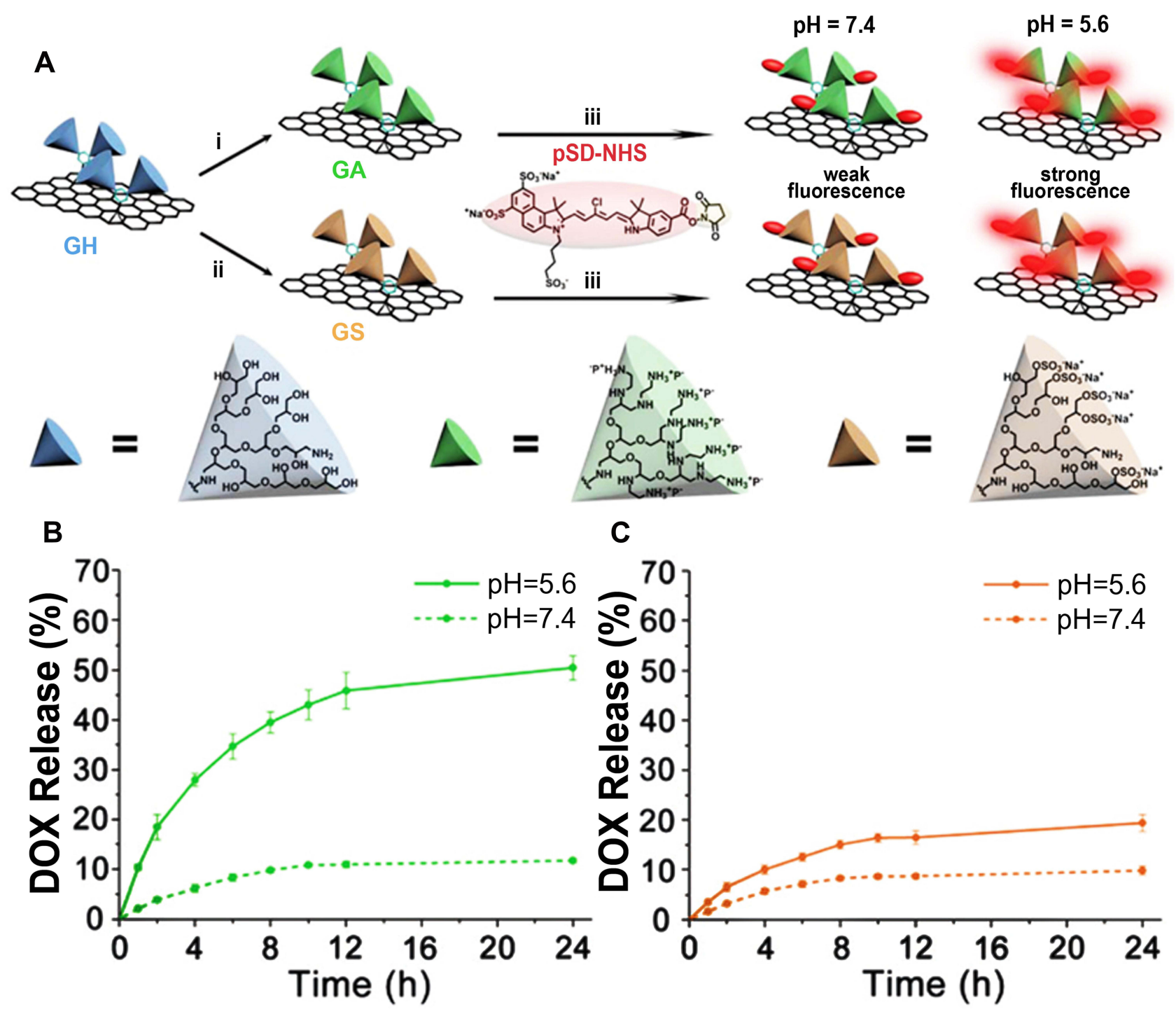

Figure 9 (A) Schematic representation of the synthesis of the polyglycerol amine functionalized graphene sheets (GA), polyglycerol sulfate-functionalized graphene sheets (GS) and conjugation of $\mathrm{pH}$-sensitive dye to the GA and GS (GAD, GSD). Information regarding the synthesis these graphene platforms can be found in ref. ${ }^{166}$ In vitro release profile of DOX from the GAD (B) and GSD (C) at $37^{\circ} \mathrm{C}$ in various media.

Notes: Reproduced with permission of Royal Society of Chemistry from Tu Z, Wycisk V, Cheng C, Chen W, Adeli M, Haag R. Functionalized graphene sheets for intracellular controlled releaseof therapeutic agents. Nanoscale. 2017;9:18931-18939.131 Copyright 2017, Advanced Functional Materials; permission conveyed through Copyright Clearance Center,Inc.

(LC-EM) helps to evaluate living tissues with high magnifications. ${ }^{193,194}$ Graphene and its derivatives, due to their interesting optical properties, have shown a high potential in this research field. ${ }^{195,196}$ They can be used for bioimaging in two ways: i) by inherent optical properties such as fluorescence quenching and Raman signals, ii) by loading fluorophores and fluorescent drugs onto their surface. $^{197,198}$

Graphene due to its zero-bandgap energy is not photoluminescent but graphene derivatives such as GO possess a significant band-gap and show the photoluminescence property. ${ }^{199}$ They emit a broad range of fluorescence from ultra violet (UV) to NIR. ${ }^{200}$ One of the promising properties of graphene derivatives is their ability to quench most types of fluorescence materials. ${ }^{201}$ These two features make graphene and its derivatives unique platforms for bioimaging. It is shown that charge transfer from the fluorophore to GO is the main reason for the fluorescence quenching and FERT (resonance energy transfer). ${ }^{202,203}$ Functionalization by a variety of materials, such as polymers, proteins, nucleic acids, peptides, and nanoparticles improves the physicochemical properties of graphenebased bioimaging probes. ${ }^{204-206}$ These compounds improve biocompatibility, loading capacity, water 


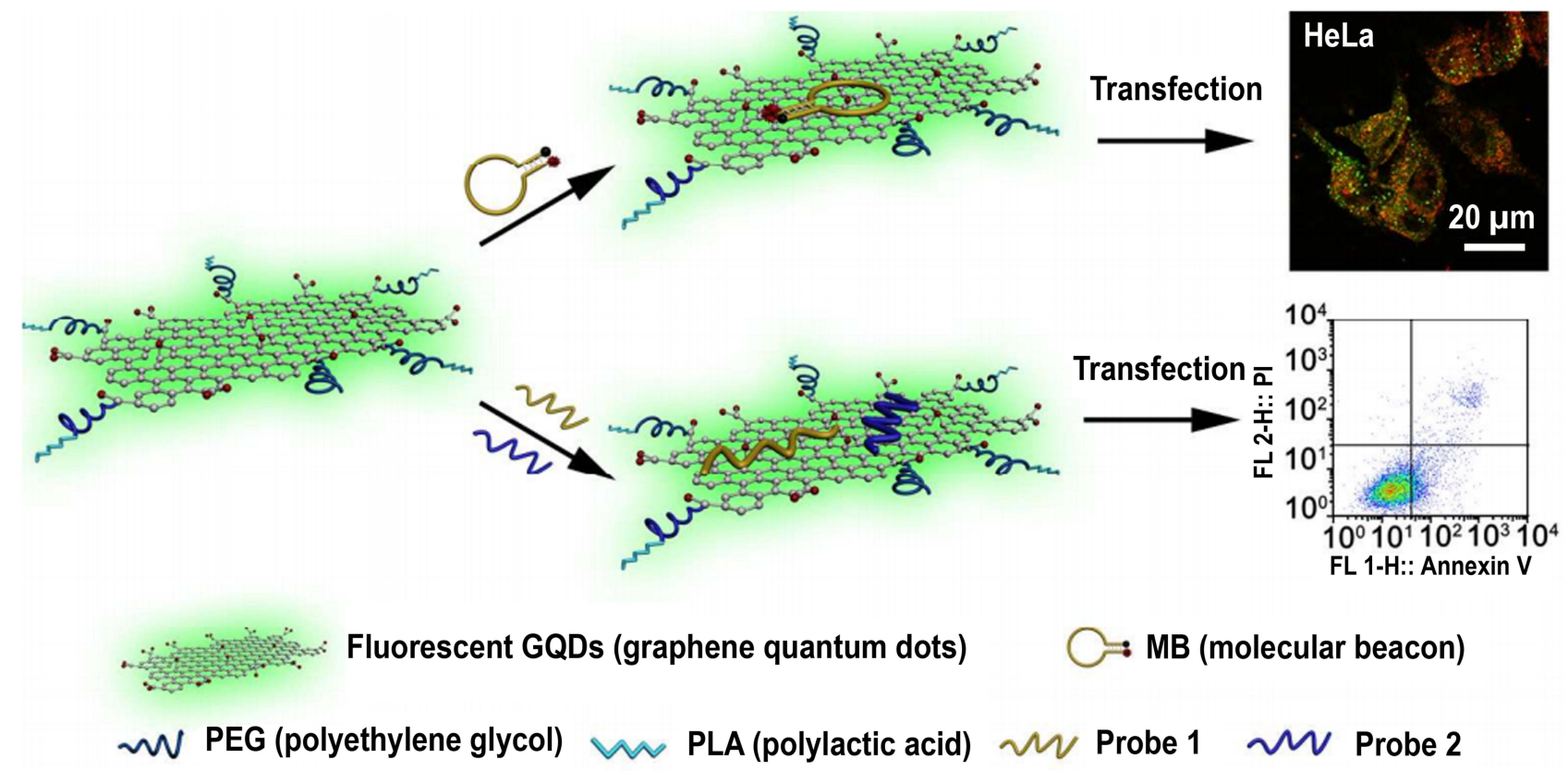

Figure 10 Schematic presentation of the functionalization of QDs by poly(l-lactide)-PEG and their application for cell imaging.

Notes: A strong signal for the functionalized QDs can be seen in HeLa cells. Low toxicity has also been observed for this material. Gene probes were loaded onto the surface of functionalized QDs with $\Pi-\Pi$ interaction. The uptake of probes by HeLa cells can be controlled by the intrinsic photoluminescence of QDs, while the fluorescence of the gene probe applied to identify the target is used to monitor gene regulation. Probe $\mathrm{I}$ is an inhibitor probe of miRNA-2I and probe 2 is survivin antisense oligodeoxynucleotide. Reproduced with permission from Dong H, Dai W, Ju H, et al. Multifunctional poly (I-lactide)-polyethylene glycol-grafted graphene quantum dots for intracellular microRNA imaging and combined specific-gene-targeting agents delivery for improved therapeutics. ACS Appl Mater Interfaces. 20I5;7:II0I5-II023. ${ }^{208}$ Copyright @ 2015, American Chemical Society.

solubility, specificity, or sensitivity of graphene-based platforms and improve their performance as bioimaging tools. ${ }^{207}$ Dong et al have developed a multifunctional graphene quantum dots-polymer for cell imaging. ${ }^{208}$ They have used poly(L-lactide) (PLA) and PEG-grafted GQDs for microRNAs imaging analysis (Figure 10). Functionalization of GQDs with these polymers has created a nanocomposite with stable photoluminescence over a wide range of $\mathrm{pH}$, which is extremely important for cell imaging. The results of cell experiments have shown low cytotoxicity and high biocompatibility for this nanocomposite, qualifying it for future bioimaging investigations.

\section{Graphene-Polymer Platforms in Photothermal and Photodynamic Therapy} Graphene and its derivatives are able to absorb NIR laser irradiation and generate heat efficiently. Therefore, they have been widely used as photosensitizing agents for photothermal therapy. This technique in combination with chemotherapy shows synergic therapeutic effect. ${ }^{209-214}$ Cheon et al have developed a combinational photochemotherapy to enhance therapeutic efficacy of DOX. ${ }^{215}$ The bovine serum albumin (BSA)-functionalized rGO (BSA-rGO) nanosheets have exhibited a high loading efficiency for DOX and absorbance of NIR light $\left(5.5 \mathrm{~W} / \mathrm{cm}^{2}, 808 \mathrm{~nm}\right.$ for $\left.300 \mathrm{~s}\right)$. Due to the increased medium temperature at the tumor site under NIR irradiation, drug has been released from BSA-rGO-DOX and low viability of brain tumor cells with reduced chemotherapy side effects has been observed (Figure 11).

Moreover, photochemotherapy of DOX loaded PEGylated GO nanosheets and DOX loaded PEGylated mesoporous carbon nanospheres (MCN) against 4T1 cells is investigated. MCN-PEG/DOX and GO-PEG/DOX have shown less toxicity against 4T1 cells than free DOX. However, when these systems are irradiated by NIR laser $\left(1.0 \mathrm{~W} / \mathrm{cm}^{2}\right)$ for $3 \mathrm{~min}$, an increase in toxicity has been observed. Additionally, due to higher photothermal conversion efficiency $(\eta)$ and drug release rate, MCN-PEG/DOX has shown higher anticancer effect than DOX/GO-PEG. ${ }^{216}$

A photothermal agent based on folic acid-CS functionalized graphene oxide (FA-CS-GO) with high photostability and tumor-targeting ability has been reported by Jun et al. ${ }^{217}$ The hybridization of GO and CS-FA hinders the aggregation of GO, promotes cellular uptake and light absorption in this platform, and enhances the PTT effects of FA-CS-GO. The surface temperature of tumors treated with FA-CS-GO 


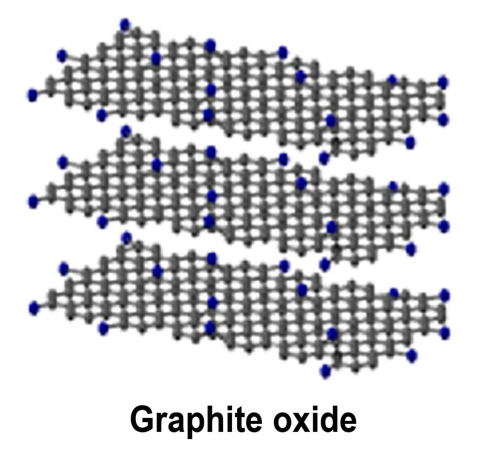

Graphite oxide

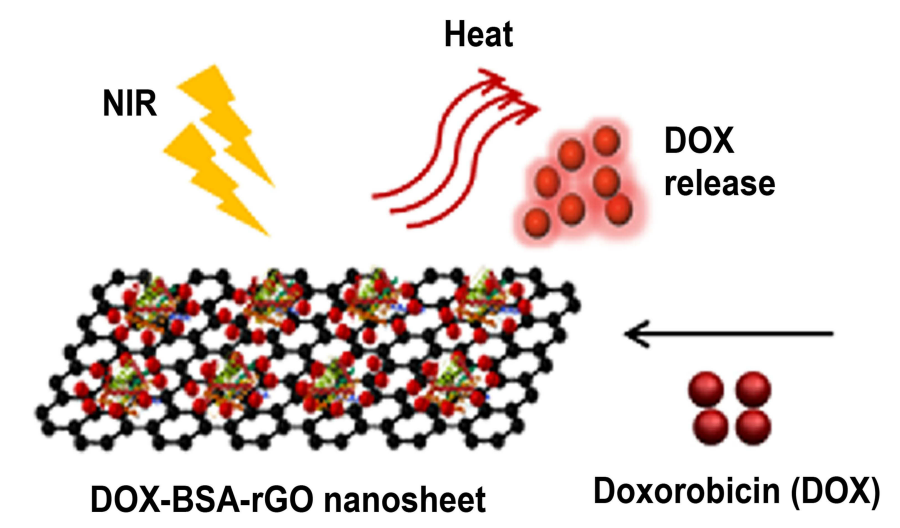

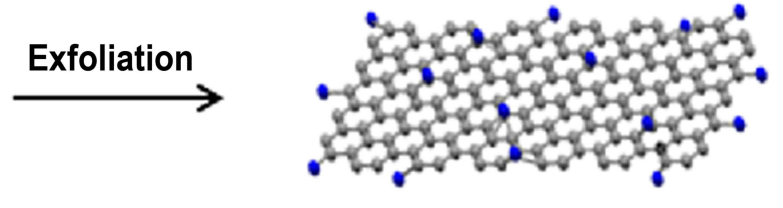

Graphene oxide

(GO)
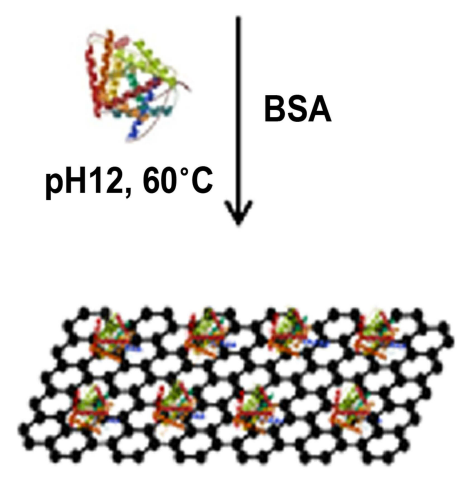

BSA-rGO nanosheet

Figure I I Schematic representation of the synthesis of DOX-BSA-rGO as a light sensitive drug delivery system for chemo-photothermal therapy. Notes: Albumin is attached onto the surface of exfoliated GO and DOX is loaded onto the surface of BSA-rGO nanosheets. This system has enhanced therapeutic efficacy of DOX drug due to the synergic effect of chemotherapy and photothermal therapy. Reproduced with permission from Cheon YA, Bae JH, Chung BG. Reduced graphene oxide nanosheet for chemo-photothermal therapy. Langmuir. 2016;32:2731-2736. ${ }^{215}$ Copyright (C 2016, American Chemical Society.

increased to $57.6{ }^{\circ} \mathrm{C}$ under laser irradiation $\left(2.0 \mathrm{~W} / \mathrm{cm}^{2}\right)$ within $5 \mathrm{~min}$. The viability of tumors treated with FA-CS$\mathrm{GO}+$ laser decreased dramatically, in comparison with laser irradiation in the absence of this platform.

The combination of graphene mediated PTT with immunotherapy has resulted in very promising results for the treatment of metastatic tumors. $\mathrm{Fe}_{3} \mathrm{O}_{4}$ nanoparticles (FNPs)/rGO/PEG (FNPs/rGO-PEG) nanocomposite are developed as multimodal agents for MRIguided photothermal-immunotherapy. The combination of FNPs/rGO-PEG nanocomposite with NIR light through reduction of tumor macrophages and photothermal therapy has promoted antitumor immune response. $^{218}$ The surface tumor temperature in FNPs/ rGO-PEG-injected mice has reached to $59^{\circ} \mathrm{C}$ after NIR

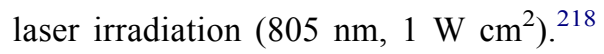

Photodynamic therapy (PDT) is an efficient method for tumor suppression. In this strategy, reactive oxygen species (ROS) are generated by photosensitizer (PS) upon visible light or laser absorption and destroy tumor cells at target sites. $^{219,220}$ To control ROS generation and enhance cellular uptake of photosensitizers, reactive agents including porphyrins, chlorins, and dyes are conjugated to graphene platforms. ${ }^{219,221,222}$ Moreover, multimodal therapies combined with PDT such as chemo-photodynamic therapy (PDT), immunotherapies-photodynamic therapy (PDT), and photothermal therapy (PTT)-photodynamic therapy (PDT) have been used for strong antitumor activity. Nanographene oxides (NGOs) with TPE (AIE) photosensitizers were synthesized as powerful tool for multimodal imaging-guided PDT. ${ }^{223}$ NGP-TPEred nanoparticles under $450 \mathrm{~nm}$ laser irradiation have shown a significant tumor inhibition both in vitro and in vivo. In another study, the chemo-PDT mediated by photosensitizer indocyanine green (ICG) and folic acid conjugated GO-PEG co-loaded with MTH1 inhibitor (TH287) and DOX has been developed for the targeted therapy of osteosarcoma tumor. MTH1 protein with controlled ROS production has been shown to be a highly synergistic chemo-photodynamic therapy. ${ }^{224}$

Furthermore, graphene quantum dots (GQDs) and graphene oxide quantum dots (GOQDs) with the size range of $1.5-5.5 \mathrm{~nm}$ have reduced skin cancer (B16F10) cells and 
breast cancer (MCF-7) cell viability about 90\% when combined with UV irradiation (365 nm) for $5 \mathrm{~min}^{225}$

\section{Graphene-Polymer Hybrids for Gene and Biomolecules Delivery}

Some human diseases stem from defective genes. In gene therapy, effective treatments of genetic diseases, nucleic acids, and genetic materials are encapsulated by nanocarriers and delivered to the desired sites in the cell. ${ }^{226}$ Gene delivery is a process through which foreign DNA is transferred into target cells to express an exogenous gene. ${ }^{227}$ Due to low bioavailability and enzymatic degradation of DNA, it should be delivered to the cells by a suitable carrier. Gene delivery systems are categorized into: viral, non-viral, and oncolytic viral vectors. $^{228}$ Viral gene delivery systems are composed of modified viruses which are not able to replicate. The most studied viral vectors for DNA delivery are including adenoviruses (AV), adeno-associated viruses (AAV), retroviruses (RV), lentiviruses (LV), and herpes simplex viruses (HSV). Their analogs for RNA delivery are human foamy virus (HFV), oncoretro-viral vectors, and lenti-viral vectors. ${ }^{229}$ Another type of gene delivery system is oncolytic viral vectors that represent an ideal platform for gene delivery. These viruses can occur either naturally or can be engineered as natural viruses in the laboratory. ${ }^{230}$ The first oncolytic virus was approved by the US Food and Drug Administration in $2015 .^{231}$ In contrast, non-viral vectors are an alternative to virus-based systems, although they have poor transfection efficiency compared to viral vectors. Non-viral vectors, such as polymers, show significantly lower cytotoxicity. They are able to carry large DNA molecules and can be produced costeffectively in large quantity. ${ }^{232,233}$ These vectors are generally prepared by both chemical and physical methods. Physical methods are usually performed via physical force to increase permeability of the cell membrane. The most important physical methods are microinjection, electroporation, ultrasound, and gene gun. ${ }^{234,235}$ Chemical methods utilize cationic polymers, cationic lipids, liposomes, and cell-penetrating peptides to deliver genes into cells. ${ }^{236-238}$ Many gene delivery systems have been designed based on cationic polymers, such as PEI. $^{239-241}$ Due to $\mathrm{pH}$ buffering capacity, this polymer is one of the most important non-viral polymeric vectors for gene delivery. This sustainable buffering capacity below physiological $\mathrm{pH}$ helps condense DNA to escape the endosomal barrier while avoiding lysosomal degradation. ${ }^{242}$ PEI due to lack of degradability has high toxicity for biomedical applications. To solve this problem, a number of PEI polymers with biodegradable segments in their backbone have been synthesized. Graphene is also used to design non-viral gene transfer systems. These systems have been proposed as efficient 2D non-viral gene transfer vectors, because their outstanding properties $^{243}$ such as facile and versatile chemical functionalization, protection of nucleic acid from enzymatic degradation, and fast cellular uptake result in efficient gene transfection into the target cells. ${ }^{244-246}$ In order to improve the biocompatibility and bio-stability of graphene platforms as well as their ability for the efficient transfection of genes, they have been modified with various polymers and ligands. ${ }^{247,248}$

There are a large number of studies regarding graphenepolymer platforms for gene delivery application. In 2018, an efficient non-viral gene delivery system was designed using PEI functionalized GO (GO-PEI) loaded with miR-7b by Dou et al which exhibited excellent transfection efficiency with low cytotoxicity. ${ }^{249}$ The results have shown that GOPEI could efficiently deliver miR-7b plasmid into bone marrow macrophages. Animal study has demonstrated that preserved preosteoclast by GO-PEI-miR-7b enhanced bone vascularization in ovariectomized mice.

GO-PEI nanostructure has been fabricated as a gene delivery and bioimaging vector by Kim et al. ${ }^{250}$ Polyethylenimine as a cationic polymer, which has been widely used as a non-viral gene delivery vector, is conjugated to GO surface to improve its interactions with negatively charged genes. Combination of branched PEI and GO results in a hybrid system with enhanced transfection efficiency and photoluminescence property for simultaneous gene delivery and bioimaging (Figure 12). Branched PEI exhibits high transfection efficiency due to enhanced cellular uptake and a high level of endosomal escape. However, due to the high cytotoxicity of high molecular weight branched PEI (HMWBPEI), their use as effective gene delivery systems is limited. In contrast, low molecular weight branched PEI (HMWBPEI) shows poor transfection efficacy, while it has low cytotoxicity. When LMW BPEI is conjugated to GO, it demonstrated good cellular uptake and transfection efficiency with low cytotoxicity. The gene transfection efficiency is evaluated using luciferase gene expression assays. The results exhibited a low gene transfection for the individual pristine GO and LMW BPEI and a high transfection for HMW BPEI and BPEI-GO. High transfection efficiency of BPEI-GO is due to the effect of LMW BPEI conjugated to $\mathrm{GO}$ and formation of a stable polyelectrolyte complex with plasmid DNA.

In general, it can be concluded that polymer-functionalized graphene-based carriers have been widely applied in 


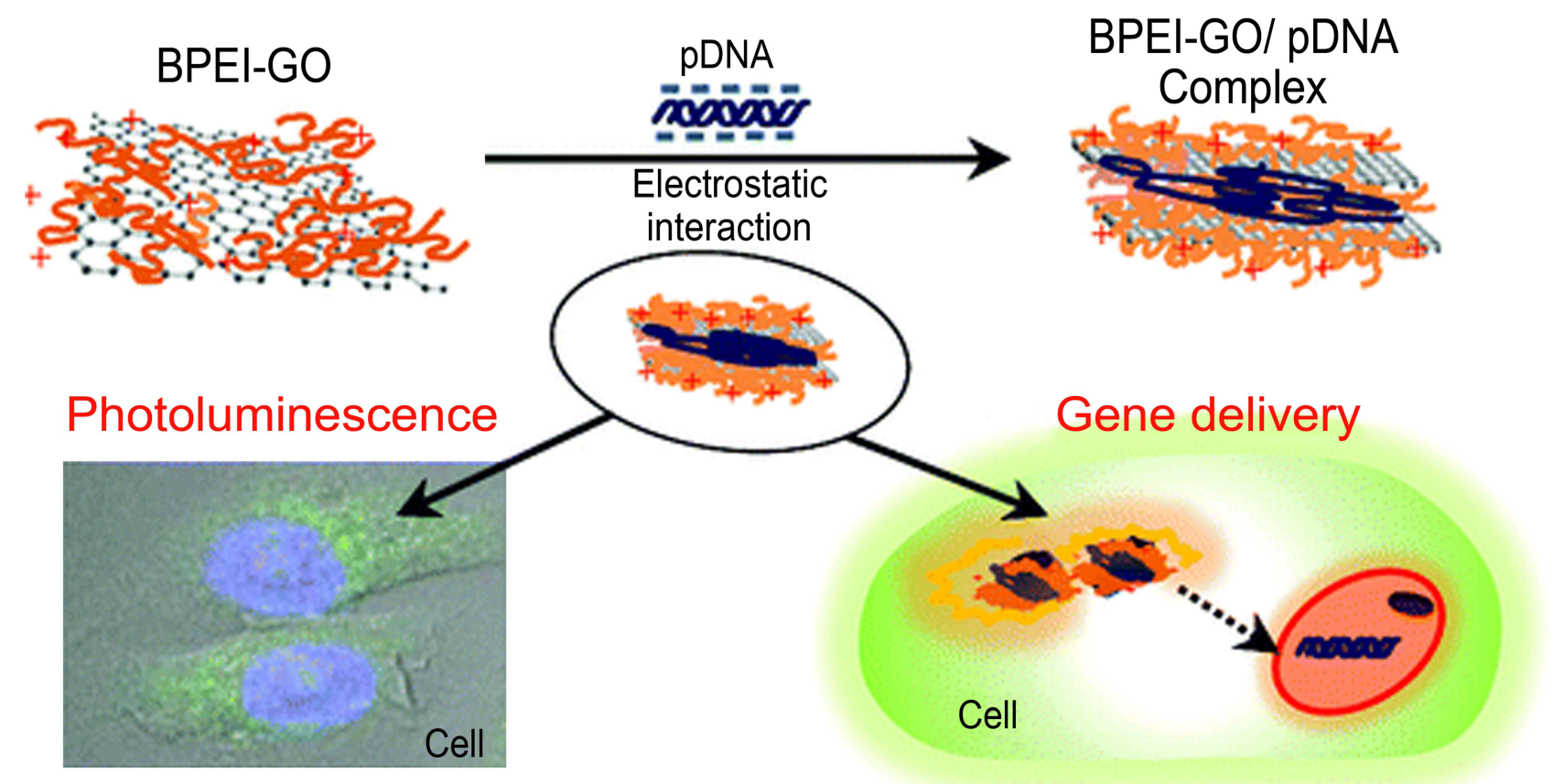

Figure 12 Schematic presentation of fabrication of GO-based gene delivery system through covalent attachment of LMW BPEI to this platform.

Notes: Conjugation of BPEI to GO enhances the photoluminescence properties of GO and improves the cellular uptake and transfection efficiency of the system. Therefore, BPEI-GO can be applied as bioimaging reagent and non-viral gene delivery vector simultaneously. Reproduced with permission from Kim H, Namgung R, Singha K, Oh IK, Kim WJ. Graphene oxide-polyethylenimine nanoconstruct as a gene delivery vector and bioimaging tool. Bioconjug Chem. 201 I;22:2558-2567. ${ }^{250}$ Copyright (C) 201 I, American Chemical Society.

gene delivery to treat various diseases including cancer, ${ }^{251}$ osteoporosis, ${ }^{252}$ and myocardial infarction. ${ }^{253}$ A variety of macromolecules including cationic polymers, dendrimers, chitosan, and peptides have been used to modify graphene derivatives for efficient gene transfection. ${ }^{254-256}$

\section{Graphene-Metal Platforms}

Graphene derivatives with high surface area provide ideal platforms to immobilize various metal nanoparticles (MNPs) including $\mathrm{Au}, \mathrm{Fe}, \mathrm{Pt}, \mathrm{Gd}, \mathrm{Pd}$, etc. in a sheet-like structure. ${ }^{257,258}$ Graphene/metal hybrids are investigated extensively for cancer therapy and imaging including photoacoustic imaging, PTT, thermomechanical, and surface enhanced Raman signals (SERS). Various approaches including in situ reduction, hydrothermal, electrochemical, physical vapor deposition, ex situ and wrapping MNPs have been reported to synthesize graphene/metal hybrids. ${ }^{259}$

In this regard, graphene-AuNPs hybrids have attracted a great deal of attention for various medical applications owing to their unique optoelectronic properties. ${ }^{260-262}$ Graphene-AuNPs hybrids are used as biosensors for the detection and diagnosis of cancer cells, due to their prominent surface plasmon resonance (SPR), ${ }^{263}$ NIR emission, quenching effect, adsorption of bioreceptors, enzyme mimic- peroxidase activities, improved electron transfer rate, and conductivity of both graphene and AuNPs. ${ }^{264}$ Moreover, GOAuNPs are reported as electrochemical immunosensors for detection of various cancer markers including CEA, CA125, P53, PSA, AFP, and Vascular endothelial growth factor (VEGF) $150 .{ }^{265-267}$ As an example, rGO/thionine/AuNPs hybrid has been used to fabricate immunosensors for the detection of cancer antigen 125 (CA125). ${ }^{268}$ This fabricated immunosensor has demonstrated low detection limits $(0.01$ $\mathrm{U} \mathrm{mL}-1$ ), high reliability and accuracy. Moreover, various hybrids of GO-AuNPs are explored for fabrication of genobiosensors for detection of DNA, miRNA-21, and plasma miR-155. ${ }^{269-271}$ On the other hand, graphene/AuNPs are widely used for photothermal therapy (PTT) and photodynamic therapy (PDT) owing to the synergic effect of both components such as strong NIR optical absorption, high NIR light-to-heat conversion, and ROS production. ${ }^{272,273}$

Magnetic graphene hybrids, particularly graphene/iron oxide, have shown synergistic therapeutic effect. ${ }^{274,275}$ It is demonstrated that graphene $/ \mathrm{Fe}_{2} \mathrm{O}_{3}$ NPs hybrids can serve as MRI contrast and diagnosis agents. ${ }^{276,277}$ Besides efficient diagnostic applications, graphene/ $\mathrm{Fe}_{2} \mathrm{O}_{3} \mathrm{NPs}$ hybrids have been investigated as magnetically targeted drug delivery systems with simultaneous photothermal effect. ${ }^{278,279}$ Many 
studies have shown that drug-loaded graphene $/ \mathrm{Fe}_{2} \mathrm{O}_{3}$ systems can be effectively accumulated at the targeted tumor site by applying an external magnetic field. ${ }^{275,280,281}$ Moreover, under external magnetic field these systems have exhibited enhanced release of the drug at the targeted tumor site owing to heat generated by the $\mathrm{Fe}_{3} \mathrm{O}_{4} \mathrm{NPs}$ and deformation of the nanocarrier. Based on these outcomes, magnetic graphene hybrids have been supposed as safe and excellent tools for imaging of cancer cells, drug delivery, and hyperthermia. ${ }^{279,282-285}$

Lanthanide-based nanomaterials, particularly gadolinium, are another class of widely explored metals as contrast agents in MRI. ${ }^{286-288}$ Conjugation of gadolinium onto the surface of graphene-based materials endows new properties and enhances their magnetic, luminescence, and therapeutic properties. Due to its outstanding properties, graphene/GdNPs hybrid is one of the most promising nanomaterials for biomedicine applications including photodynamic/photothermal therapy, biosensing, and bioimaging. ${ }^{289,290}$

Extensive studies have pointed out that Pd-based nanomaterials are excellent platforms for promoting the chemotherapeutic effects of graphene drug delivery systems. Tumor model studies have shown a high performance of graphene/ PdNPs hybrids for diagnosis and treatment of cancers. ${ }^{291,292}$

\section{Conclusion}

This review aims to explain the advantages and recent progresses in graphene-based platforms for different biomedical applications including drug and gene delivery as well as bioimaging. There is a great deal of attention to use graphene and its derivatives in biomedicine. However, an extensive study on the toxicity and health risks of this class of nanomaterials should be performed to diminish the risk of their long-term side effects. To achieve this goal, the key point is to produce a highly defined graphene family in terms of number of layers, surface area, and functionality.

\section{Acknowledgment}

The authors would like to thank Iran's Science Elites Federation for their financial support.

\section{Disclosure}

The authors reported no conflicts of interest for this work.

\section{References}

1. Bray F, Ferlay J, Soerjomataram I, Siegel RL, Torre LA, Jemal A. Global cancer statistics 2018: GLOBOCAN estimates of incidence and mortality worldwide for 36 cancers in 185 countries. CA Cancer J Clin. 2018;68:394-424. doi:10.3322/caac.21492
2. Zaorsky NG, Churilla T, Egleston B, et al. Causes of death among cancer patients. Ann Oncol. 2017;28:400-407. doi:10.1093/ annonc/mdw604

3. Farhood B, Geraily G, Alizadeh A. Incidence and mortality of various cancers in Iran and compare to other countries: a review article. Iran J Public Health. 2018;47:309.

4. Nagai H, Kim YH. Cancer prevention from the perspective of global cancer burden patterns. $J$ Thorac Dis. 2017;9:448. doi: $10.21037 /$ jtd.2017.02.75

5. Rawla P, Sunkara T, Barsouk A. Epidemiology of colorectal cancer: incidence, mortality, survival, and risk factors. Prz Gastroenterol. 2019;14:89.

6. Khairunnahar L, Hasib MA, Rezanur RHB, Islam MR, Hosain MK. Classification of malignant and benign tissue with logistic regression. Inform Med Unlocked. 2019;16:100189. doi:10.1016/j.imu.2019.100189

7. Teramoto A, Tsujimoto M, Inoue $\mathrm{T}$, et al. Automated classification of pulmonary nodules through a retrospective analysis of conventional CT and two-phase PET images in patients undergoing biopsy. Asia Oceania J Nucl Med Biol. 2019;7:29. doi:10.22038/AOJNMB.2018.12014

8. Beiranvand Z, Bani F, Kakanejadifard A, et al. Anticancer drug delivery systems based on specific interactions between albumin and polyglycerol. RSC Adv. 2016;6:11266-11277. doi:10.1039/ C5RA25463A

9. Mohammadifar E, Kharat AN, Adeli M. Polyamidoamine and polyglycerol; their linear, dendritic and linear-dendritic architectures as anticancer drug delivery systems. $J$ Mater Chem $B$. 2015;3:3896-3921. doi:10.1039/C4TB02133A

10. Pucci C, Martinelli C, Ciofani G. Innovative approaches for cancer treatment: current perspectives and new challenges. Ecancermedicalscience. $\quad 2019 ; 13 . \quad$ doi:10.3332/ecancer.20 19.961

11. Chakraborty C, Sharma AR, Sharma G, Sarkar BK, Lee -S-S. The novel strategies for next-generation cancer treatment: miRNA combined with chemotherapeutic agents for the treatment of cancer. Oncotarget. 2018;9:10164. doi:10.18632/ oncotarget.24309

12. Pedrosa P, Mendes R, Cabral R, Martins LM, Baptista PV, Fernandes AR. Combination of chemotherapy and Au-nanoparticle photothermy in the visible light to tackle doxorubicin resistance in cancer cells. Sci Rep. 2018;8:1-8. doi:10.1038/s41598-018-29870-0

13. Liang X-J, Chen C, Zhao Y, Wang PC. Circumventing tumor resistance to chemotherapy by nanotechnology. In: Zhou J, editor. Multi-Drug Resistance in Cancer. Springer; 2010:467-488. doi:10.1007/978-1-60761-416-6_21

14. Tu Z, Qiao H, Yan Y, et al. Directed graphene-based nanoplatforms for hyperthermia: overcoming multiple drug resistance. Angew Chem. 2018;130:11368-11372. doi:10.1002/ ange.201804291

15. Yu W, Liu R, Zhou Y, Gao H. Size-tunable strategies for a tumor targeted drug delivery system. ACS Cent Sci. 2020;6:100-116. doi:10.1021/acscentsci.9b01139

16. Zhao L, Xing Y, Wang R, Yu F, Yu F. Self-assembled nanomaterials for enhanced phototherapy of cancer. ACS Applied Bio Mater. 2019;3:86-106. doi:10.1021/acsabm.9b00843

17. Zhou Q, Zhang L, Wu H. Nanomaterials for cancer therapies. Nanotechnology Reviews. 2017;6:473-496.

18. Adeli M, Rasoulian B, Saadatmehr F, Zabihi F. Hyperbranched poly (citric acid) and its application as anticancer drug delivery system. J Appl Polym Sci. 2013;129:3665-3671. doi:10.1002/ app. 39028

19. Dang Y, Guan J. Nanoparticle-based drug delivery systems for cancer therapy. Smart Mater Med. 2020;1:10-19. doi:10.1016/j. smaim.2020.04.001 
20. Chegeni BK, Kakanejadifard A, Abedi F, Kabiri R, Daneshnia F, Adeli M. pH-sensitive supramolecular copolydendrimers, new anticancer drug delivery system. Colloid Polym Sci. 2014; 292:3337-3346. doi:10.1007/s00396-014-3398-2

21. Eskandari M, Hosseini SH, Adeli M, Pourjavadi A. Polymerfunctionalized carbon nanotubes in cancer therapy: a review. Iran Polym J. 2014;23:387-403. doi:10.1007/s13726-014-0228-9

22. Adeli M, Soleyman R, Beiranvand Z, Madani F. Carbon nanotubes in cancer therapy: a more precise look at the role of carbon nanotube-polymer interactions. Chem Soc Rev. 2013;42: 5231-5256. doi:10.1039/c3cs35431h

23. Souri Z, Adeli M, Mehdipour E. Two-dimensional MoS 2: a platform for constructing three-dimensional structures using RAFT polymerization. New J Chem. 2020;44:17961-17969. doi:10.1039/D0NJ03285A

24. Faghani A, Gholami MF, Trunk M, et al. Metal-assisted and solvent-mediated synthesis of two-dimensional triazine structures on Gram Scale. J Am Chem Soc. 2020;142:12976-12986. doi:10.1021/jacs.0c02399

25. Sattari S, Beyranvand S, Soleimani K, et al. Boronic acid-functionalized two-dimensional MoS2 at biointerfaces. Langmuir. 2020;36:6706-6715. doi:10.1021/acs.langmuir.0c00776

26. Daneshnia S, Adeli M, Yari A, Shams A, Donskyi IS, Unger WE. Low temperature functionalization of two-dimensional boron nitride for electrochemical sensing. Mater Res Express. 2019;6:095076. doi:10.1088/2053-1591/ab317b

27. Daneshnia S, Adeli M, Mansourpanah Y. Gram scale and room temperature functionalization of boron nitride nanosheets for water treatment. Nano. 2019;14:1950107. doi:10.1142/S1793 292019501078

28. Souri Z, Adeli M, Mehdipour E, et al. Covalent decoration of MoS2 platforms by silver nanoparticles through the reversible addition-fragmentation chain transfer reaction. Langmuir. 2021;37(11):3382-3390. doi:10.1021/acs.langmuir.0c03518

29. Patra JK, Das G, Fraceto LF, et al. Nano based drug delivery systems: recent developments and future prospects. J Nanobiotechnology. 2018;16:1-33.

30. Orecchioni M, Cabizza R, Bianco A, Delogu LG. Graphene as cancer theranostic tool: progress and future challenges. Theranostics. 2015;5:710. doi:10.7150/thno.11387

31. Shareena TPD, McShan D, Dasmahapatra AK, Tchounwou PB. A review on graphene-based nanomaterials in biomedical applications and risks in environment and health. Nano Micro Lett. 2018;10:1-34. doi:10.1007/s40820-017-0154-4

32. Donskyi IS, Chen Y, Nickl P, et al. Self-degrading graphene sheets for tumor therapy. Nanoscale. 2020;12:14222-14229. doi:10.1039/D0NR02159H

33. Gheybi H, Sattari S, Soleimani K, Adeli M. Graphene-dendritic polymer hybrids: synthesis, properties, and applications. J Iran Chem Soc. 2020;17:735-764.

34. Schedin F, Geim AK, Morozov SV, et al. Detection of individual gas molecules adsorbed on graphene. Nat Mater. 2007;6: 652-655. doi:10.1038/nmat 1967

35. Olabi A, Abdelkareem MA, Wilberforce T, Sayed ET. Application of graphene in energy storage device-A review. Renew Sustain Energy Rev. 2021;135:110026.

36. Wang B, Ruan T, Chen Y, et al. Graphene-based composites for electrochemical energy storage. Energy Storage Mater. 2020;24: $22-51$.

37. Tehrani Z, Whelan S, Mostert A, et al. Printable and flexible graphene $\mathrm{pH}$ sensors utilising thin film melanin for physiological applications. 2D Mater. 2020;7:024008. doi:10.1088/2053-1583/ab72d5

38. Farooqi BA, Yar M, Ashraf A, Farooq U, Ayub K. Graphenepolyaniline composite as superior electrochemical sensor for detection of cyano explosives. Eur Polym J. 2020;138:109981. doi:10.1016/j.eurpolymj.2020.109981
39. Suvarnaphaet P, Pechprasarn S. Graphene-based materials for biosensors: a review. Sensors. 2017;17:2161.

40. Tonelli FM, Goulart VA, Gomes KN, et al. Graphene-based nanomaterials: biological and medical applications and toxicity. Nanomedicine. 2015;10:2423-2450. doi:10.2217/nnm.15.65

41. Priyadarsini S, Mohanty S, Mukherjee S, Basu S, Mishra M. Graphene and graphene oxide as nanomaterials for medicine and biology application. $J$ Nanostructure Chem. 2018;8:123-137. doi:10.1007/s40097-018-0265-6

42. Donskyi IS, Azab W, Cuellar-Camacho JL, et al. Functionalized nanographene sheets with high antiviral activity through synergistic electrostatic and hydrophobic interactions. Nanoscale. 2019;11:15804-15809. doi:10.1039/C9NR05273A

43. Beyranvand S, Gholami MF, Tehrani AD, Rabe P Jr, Adeli M. Construction and evaluation of a self-calibrating multiresponse and multifunctional graphene biosensor. Langmuir. 2019;35:10461-10474. doi:10.1021/acs.langmuir.9b00915

44. Tan KH, Sattari S, Beyranvand S, et al. Thermoresponsive amphiphilic functionalization of thermally reduced graphene oxide to study graphene/bacteria hydrophobic interactions. Langmuir. 2019;35:4736-4746. doi:10.1021/acs.langmuir.8b03660

45. Mohammad-Beigi H, Hosseini A, Adeli M, et al. Mechanistic understanding of the interactions between nano-objects with different surface properties and $\alpha$-synuclein. ACS Nano. 2019;13:3243-3256. doi:10.1021/acsnano.8b08983

46. Soleimani K, Tehrani AD, Adeli M, Sattari S. Convenient method for preparation of a new absorbent based on biofunctionalized graphene oxide hydrogels using nitrene chemistry and click reaction. Iran Polym J. 2018;27:689-699. doi:10.1007/s13726-018-0645-2

47. Wang Y, Qiu M, Won M, et al. Emerging 2D material-based nanocarrier for cancer therapy beyond graphene. Coord Chem Rev. 2019;400:213041. doi:10.1016/j.ccr.2019.213041

48. de Melo-diogo D, Lima-Sousa R, Alves CG, Costa EC, Louro RO, Correia IJ. Functionalization of graphene family nanomaterials for application in cancer therapy. Colloids Surf B Biointerfaces. 2018;171:260-275. doi:10.1016/j.colsurfb.2018.07.030

49. Wang W, Meng Z, Liang R, et al. A dynamically tunable plasmonic multi-functional device based on graphene nano-sheet pair arrays. $O p t$ Commun. 2018;415:130-134. doi:10.1016/j.optcom.2018.01.049

50. Peng L, Li X-F, Gao X, Jiang X, Li S-M. Methodology for the design of a multi-functional device with switchable absorption and polarization conversion modes by graphene and metallic metasurfaces. Opt Mater Express. 2019;9(2):687-705. doi:10.1364/OME.9.000687

51. Tu Z, Guday G, Adeli M, Haag R. Multivalent interactions between 2D nanomaterials and biointerfaces. Adv Mater. 2018;30:1706709. doi:10.1002/adma.201706709

52. De D, Das CK, Mandal D, et al. Curcumin complexed with graphene derivative for breast cancer therapy. ACS Applied Bio Mater. 2020;3:6284-6296. doi:10.1021/acsabm.0c00771

53. Yadav N, Kannan D, Patil S, Singh S, Lochab B. Amplified activity of artesunate mediated by iron oxide nanoparticles loaded on a graphene oxide carrier for cancer therapeutics. ACS Applied Bio Mater. 2020;3:6722-6736. doi:10.1021/acsabm.0c00632

54. Yang Z, Yang D, Zeng K, et al. Simultaneous delivery of antimiR-21 and doxorubicin by graphene oxide for reducing toxicity in cancer therapy. ACS Omega. 2020;5:14437-14443. doi:10.1021/acsomega.0c01010

55. Liu L, Zhang J, Zhao J, Liu F. Mechanical properties of graphene oxides. Nanoscale. 2012;4:5910-5916. doi:10.1039/ $\mathrm{c} 2 \mathrm{nr} 31164 \mathrm{j}$

56. Mousavi SM, Hashemi SA, Ghasemi Y, Amani AM, Babapoor A, Arjmand O. Applications of graphene oxide in case of nanomedicines and nanocarriers for biomolecules: review study. Drug Metab Rev. 2019;51:12-41. doi:10.1080/03602532.2018.1522328 
57. Wu J, Wang Y-S, Yang X-Y, et al. Graphene oxide used as a carrier for adriamycin can reverse drug resistance in breast cancer cells. Nanotechnology. 2012;23:355101. doi:10.1088/ 0957-4484/23/35/355101

58. Li X, Wang Y, Shi L, et al. A novel ECL biosensor for the detection of concanavalin A based on glucose functionalized $\mathrm{NiCo} 2 \mathrm{~S} 4$ nanoparticles-grown on carboxylic graphene as quenching probe. Biosens Bioelectron. 2017;96:113-120. doi:10.1016/j. bios.2017.04.050

59. Xiao FN, Wang M, Wang FB, Xia XH. Graphene-ruthenium (II) complex composites for sensitive ECL immunosensors. Small. 2014;10:706-716. doi:10.1002/smll.201301566

60. Zhu M, Tang Y, Wen Q, Li J, Yang P. Dynamic evaluation of cell-secreted interferon gamma in response to drug stimulation via a sensitive electro-chemiluminescence immunosensor based on a glassy carbon electrode modified with graphene oxide, polyaniline nanofibers, magnetic beads, and gold nanoparticles. Microchim Acta. 2016;183:1739-1748.

61. Wang C-I, Wu W-C, Periasamy AP, Chang H-T. Sensitive and selective DNA probe based on "turn-on" photoluminescence of C-dots@ RGO. Anal Bioanal Chem. 2014;406:6917-6923. doi:10.1007/s00216-014-7658-2

62. Yao J, Wang $H$, Chen $M$, Yang $M$. Recent advances in graphene-based nanomaterials: properties, toxicity and applications in chemistry, biology and medicine. Microchim Acta. 2019; 186:1-25

63. Tong C, Zhao C, Liu B, et al. Sensitive detection of RNase a activity and collaborative drug screening based on $\mathrm{rGO}$ and fluorescence probe. Anal Chem. 2018;90:2655-2661. doi:10. 1021/acs.analchem.7b04429

64. Alizadeh N, Salimi A, Hallaj R, Fathi F, Soleimani F. CuO/WO3 nanoparticles decorated graphene oxide nanosheets with enhanced peroxidase-like activity for electrochemical cancer cell detection and targeted therapeutics. Mater Sci Eng C. 2019;99:1374-1383. doi:10.1016/j.msec.2019.02.048

65. Yang K, Feng L, Shi X, Liu Z. Nano-graphene in biomedicine: theranostic applications. Chem Soc Rev. 2013;42:530-547. doi: $10.1039 / \mathrm{C} 2 \mathrm{CS} 35342 \mathrm{C}$

66. Zhang Y, Nayak TR, Hong H, Cai W. Graphene: a versatile nanoplatform for biomedical applications. Nanoscale. 2012;4: 3833-3842. doi:10.1039/c2nr31040f

67. Jia -P-P, Sun T, Junaid M, et al. Nanotoxicity of different sizes of graphene $(\mathrm{G})$ and graphene oxide $(\mathrm{GO})$ in vitro and in vivo. Environ Pollut. 2019;247:595-606. doi:10.1016/j.envpol.2019. 01.072

68. Zhang L, Xia J, Zhao Q, Liu L, Zhang Z. Functional graphene oxide as a nanocarrier for controlled loading and targeted delivery of mixed anticancer drugs. Small. 2010;6:537-544. doi:10.1002/ smll.200901680

69. Lammel T, Boisseaux P, Fernández-Cruz M-L, Navas JM. Internalization and cytotoxicity of graphene oxide and carboxyl graphene nanoplatelets in the human hepatocellular carcinoma cell line Hep G2. Part Fibre Toxicol. 2013;10:1-21. doi:10. 1186/1743-8977-10-27

70. Akhavan O, Ghaderi E, Akhavan A. Size-dependent genotoxicity of graphene nanoplatelets in human stem cells. Biomaterials. 2012;33:8017-8025. doi:10.1016/j.biomaterials. 2012.07.040

71. Li Y, Liu Y, Fu Y, et al. The triggering of apoptosis in macrophages by pristine graphene through the MAPK and TGF-beta signaling pathways. Biomaterials. 2012;33:402-411. doi:10.1016/ j.biomaterials.2011.09.091

72. Liao K-H, Lin Y-S, Macosko CW, Haynes CL. Cytotoxicity of graphene oxide and graphene in human erythrocytes and skin fibroblasts. ACS Appl Mater Interfaces. 2011;3:2607-2615. doi:10.1021/am200428v
73. Chowdhury SM, Lalwani G, Zhang K, Yang JY, Neville K, Sitharaman B. Cell specific cytotoxicity and uptake of graphene nanoribbons. Biomaterials. 2013;34:283-293. doi:10.1016/j. biomaterials.2012.09.057

74. Jaworski S, Sawosz E, Kutwin M, et al. In vitro and in vivo effects of graphene oxide and reduced graphene oxide on glioblastoma. Int J Nanomedicine. 2015;10:1585. doi:10.2147/ IJN.S77591

75. Gurunathan S, Han JW, Kim ES, Park JH, Kim J-H. Reduction of graphene oxide by resveratrol: a novel and simple biological method for the synthesis of an effective anticancer nanotherapeutic molecule. Int J Nanomedicine. 2015;10:2951. doi:10.2147/IJN.S79879

76. Zhao J, Wang Z, White JC, Xing B. Graphene in the aquatic environment: adsorption, dispersion, toxicity and transformation. Environ Sci Technol. 2014;48:9995-10009. doi:10.1021/es5022679

77. $\mathrm{Hu} \mathrm{W}$, Peng $\mathrm{C}$, Luo W, et al. Graphene-based antibacterial paper. ACS Nano. 2010;4:4317-4323. doi:10.1021/nn101097v

78. Sydlik SA, Jhunjhunwala S, Webber MJ, Anderson DG, Langer R. In vivo compatibility of graphene oxide with differing oxidation states. ACS Nano. 2015;9:3866-3874. doi:10.1021/ acsnano. 5 b0 1290

79. Duch MC, Budinger GS, Liang YT, et al. Minimizing oxidation and stable nanoscale dispersion improves the biocompatibility of graphene in the lung. Nano Lett. 2011;11:5201-5207. doi:10. 1021/nl202515a

80. Schinwald A, Murphy FA, Jones A, MacNee W, Donaldson K Graphene-based nanoplatelets: a new risk to the respiratory system as a consequence of their unusual aerodynamic properties. ACS Nano. 2012;6:736-746. doi:10.1021/nn204229f

81. Zhang S, Yang K, Feng L, Liu Z. In vitro and in vivo behaviors of dextran functionalized graphene. Carbon. 2011;49:4040-4049. doi:10.1016/j.carbon.2011.05.056

82. Krasteva N, Keremidarska-Markova M, Hristova-Panusheva K, et al. Aminated graphene oxide as a potential new therapy for colorectal cancer. Oxid Med Cell Longev. 2019;2019:1-15. doi: $10.1155 / 2019 / 3738980$

83. Park J, Yan M. Covalent functionalization of graphene with reactive intermediates. Acc Chem Res. 2013;46:181-189. doi:10.1021/ar300172h

84. Wang B, Su X, Liang J, et al. Synthesis of polymer-functionalized nanoscale graphene oxide with different surface charge and its cellular uptake, biosafety and immune responses in Raw264. 7 macrophages. Mater Sci Eng C. 2018;90:514-522. doi:10.1016/j. msec.2018.04.096

85. Charmi J, Nosrati H, Amjad JM, Mohammadkhani R, Danafar H. Polyethylene glycol (PEG) decorated graphene oxide nanosheets for controlled release curcumin delivery. Heliyon. 2019;5:e01466. doi:10.1016/j.heliyon.2019.e01466

86. Mendonça MCP, Soares ES, de Jesus MB, et al. PEGylation of reduced graphene oxide induces toxicity in cells of the bloodbrain barrier: an in vitro and in vivo study. Mol Pharm. 2016;13:3913-3924. doi:10.1021/acs.molpharmaceut.6b00696

87. Yang K, Wan J, Zhang S, Zhang Y, Lee S-T, Liu Z. In vivo pharmacokinetics, long-term biodistribution, and toxicology of PEGylated graphene in mice. ACS Nano. 2011;5:516-522. doi:10.1021/nn1024303

88. Shi J, Kantoff PW, Wooster R, Farokhzad OC. Cancer nanomedicine: progress, challenges and opportunities. Nat Rev Cancer. 2017;17:20.

89. Yuan D, He H, Wu Y, Fan J, Cao Y. Physiologically based pharmacokinetic modeling of nanoparticles. J Pharm Sci. 2019;108:58-72. doi:10.1016/j.xphs.2018.10.037

90. Elci SG, Jiang Y, Yan B, et al. Surface charge controls the suborgan biodistributions of gold nanoparticles. ACS Nano. 2016;10:5536-5542. doi:10.1021/acsnano.6b02086 
91. Syama S, Paul W, Sabareeswaran A, Mohanan PV. Raman spectroscopy for the detection of organ distribution and clearance of PEGylated reduced graphene oxide and biological consequences. Biomaterials. 2017;131:121-130. doi:10.1016/j.biomaterials.20 17.03 .043

92. Chen L, Wang C, Li H, Qu X, Yang S-T, Chang X-L. Bioaccumulation and toxicity of 13C-skeleton labeled graphene oxide in wheat. Environ Sci Technol. 2017;51:10146-10153. doi:10.1021/acs.est.7b00822

93. Peng H, Zhang L, Cai Z, et al. Pharmacokinetics study of isorhamnetin in rat plasma by a sensitive electrochemical sensor based on reduced graphene oxide. RSC Adv. 2017;7:36 728-36734. doi:10.1039/C7RA03632A

94. Liang S, Wang B, Li X, et al. In vivo pharmacokinetics, transfer and clearance study of graphene oxide by $\mathrm{La} / \mathrm{Ce}$ dual elemental labelling method. NanoImpact. 2020;17:100213. doi:10.1016/j. impact.2020.100213

95. Sun X, Huang C, Wang L, et al. Recent progress in graphene/ polymer nanocomposites. Adv Mater. 2020:2001105.

96. Silva M, Alves NM, Paiva MC. Graphene-polymer nanocomposites for biomedical applications. Polym Adv Technol. 2018;29:687-700. doi:10.1002/pat.4164

97. Tadyszak K, Wychowaniec JK, Litowczenko J. Biomedical applications of graphene-based structures. Nanomaterials. 2018;8:944. doi:10.3390/nano8110944

98. Donskyi IS, Nie C, Ludwig K, et al. Graphene sheets with defined dual functionalities for the strong SARS-CoV-2 interactions. Small. 2021;17(11):2007091. doi:10.1002/smll.202007091

99. Song S, Shen H, Wang Y, et al. Biomedical application of graphene: from drug delivery, tumor therapy, to theranostics. Colloids Surf B Biointerfaces. 2020;185:110596. doi:10.1016/j. colsurfb.2019.110596

100. Gheybi H, Sattari S, Soleimani K, Adeli M. Graphene-dendritic polymer hybrids: synthesis, properties, and applications. J Iran Chem Soc. 2020:1-30.

101. Tehrani AD, Adeli M, Sattari S, Soleimani K. Graphene oxidepolymer gels. In: Thakur V, Thakur M, editors. Polymer Gels. Springer; 2018:377-412.

102. Guday G, Donskyi IS, Gholami MF, et al. Scalable production of nanographene and doping via nondestructive covalent functionalization. Small. 2019;15:1805430. doi:10.1002/ smll.201805430

103. Bani F, Bodaghi A, Dadkhah A, et al. One-pot exfoliation, functionalization, and size manipulation of graphene sheets: efficient system for biomedical applications. Lasers Med Sci. 2018;33:795-802. doi:10.1007/s10103-017-2422-4

104. Faghani A, Donskyi IS, Fardin Gholami M, et al. Controlled covalent functionalization of thermally reduced graphene oxide to generate defined bifunctional 2D nanomaterials. Angew Chem. 2017;129:2719-2723. doi:10.1002/ange.201612422

105. Khani M, Mehdipour E, Faghani A, et al. Preparation of graphene oxide by cyanuric chloride as an effective and non-corrosive oxidizing agent. RSC $A d v$. 2016;6:115055-115057. doi:10.1039/ C6RA23702A

106. Maleki M, Adeli M, Kakanejadifard A, Movahedi S, Bani F. Enzymatic functionalization of nanomaterials: a strategy for engineering their surfaces. Polymer. 2013;54:4802-4806. doi:10.10 16/j.polymer.2013.07.023

107. Georgakilas V, Otyepka M, Bourlinos AB, et al. Functionalization of graphene: covalent and non-covalent approaches, derivatives and applications. Chem Rev. 2012;112:6156-6214.

108. Nanda SS, Papaefthymiou GC, Yi DK. Functionalization of graphene oxide and its biomedical applications. Crit Rev Solid State Mater Sci. 2015;40:291-315. doi:10.1080/10408436.2014.1002604
109. Strom TA, Dillon EP, Hamilton CE, Barron AR. Nitrene addition to exfoliated graphene: a one-step route to highly functionalized graphene. Chem Commun. 2010;46:4097-4099. doi:10.1039/ c001488e

110. Gao C, He H, Zhou L, Zheng X, Zhang Y. Scalable functional group engineering of carbon nanotubes by improved one-step nitrene chemistry. Chem Mater. 2009;21:360-370. doi:10.1021/ cm802704c

111. Setaro A, Adeli M, Glaeske M, et al. Preserving $\pi$-conjugation in covalently functionalized carbon nanotubes for optoelectronic applications. Nat Commun. 2017;8:1-7. doi:10.1038/ncomms14281

112. Gholami MF, Lauster D, Ludwig K, et al. Functionalized graphene as extracellular matrix mimics: toward well-defined $2 \mathrm{D}$ nanomaterials for multivalent virus interactions. Adv Funct Mater. 2017;27:1606477. doi:10.1002/adfm.201606477

113. Pei X, Zhu Z, Gan Z, et al. PEGylated nano-graphene oxide as a nanocarrier for delivering mixed anticancer drugs to improve anticancer activity. Sci Rep. 2020;10:1-15. doi:10.1038/s41598020-59624-w

114. $\mathrm{Xu} \mathrm{Z,} \mathrm{Wang} \mathrm{S,} \mathrm{Li} \mathrm{Y,} \mathrm{Wang} \mathrm{M,} \mathrm{Shi} \mathrm{P,} \mathrm{Huang} \mathrm{X.} \mathrm{Covalent}$ functionalization of graphene oxide with biocompatible poly (ethylene glycol) for delivery of paclitaxel. ACS Appl Mater Interfaces. 2014;6:17268-17276. doi:10.1021/am505308f

115. Abdollahi Z, Taheri-Kafrani A, Bahrani SA, Kajani AA. PEGAylated graphene oxide/superparamagnetic nanocomposite as a high-efficiency loading nanocarrier for controlled delivery of methotrexate. J Biotechnol. 2019;298:88-97. doi:10.1016/j. jbiotec.2019.04.006

116. Mallick A, Nandi A, Basu S. Polyethylenimine coated graphene oxide nanoparticles for targeting mitochondria in cancer cells. ACS Applied Bio Mater. 2018;2:14-19. doi:10.1021/acsabm. $8 \mathrm{~b} 00519$

117. Ren T, Li L, Cai X, Dong H, Liu S, Li Y. Engineered polyethylenimine/graphene oxide nanocomposite for nuclear localized gene delivery. Polym Chem. 2012;3:2561-2569. doi:10.1039/ c2py20343j

118. Anirudhan T, Sekhar VC, Athira V. Graphene oxide based functionalized chitosan polyelectrolyte nanocomposite for targeted and $\mathrm{pH}$ responsive drug delivery. Int $J$ Biol Macromol. 2020;150:468-479. doi:10.1016/j.ijbiomac.2020.02.053

119. Omidi S, Pirhayati M, Kakanejadifard A. Co-delivery of doxorubicin and curcumin by a $\mathrm{pH}$-sensitive, injectable, and in situ hydrogel composed of chitosan, graphene, and cellulose nanowhisker. Carbohydr Polym. 2020;231:115745. doi:10.1016/ j.carbpol.2019.115745

120. Wen $\mathrm{C}$, Cheng $\mathrm{R}$, Gong $\mathrm{T}$, et al. $\beta$-Cyclodextrin-cholic acidhyaluronic acid polymer coated $\mathrm{Fe} 3 \mathrm{O} 4$-graphene oxide nanohybrids as local chemo-photothermal synergistic agents for enhanced liver tumor therapy. Colloids Surf B Biointerfaces. 2020:111510.

121. Lima-Sousa R, de Melo-diogo D, Alves CG, et al. Hyaluronic acid functionalized green reduced graphene oxide for targeted cancer photothermal therapy. Carbohydr Polym. 2018;200: 93-99. doi:10.1016/j.carbpol.2018.07.066

122. Gu Y, Guo Y, Wang C, et al. A polyamidoamne dendrimer functionalized graphene oxide for DOX and MMP-9 shRNA plasmid co-delivery. Mater Sci Eng C. 2017;70:572-585. doi:10.1016/j.msec.2016.09.035

123. Gheybi H, Sattari S, Bodaghi A, Soleimani K, Dadkhah A, Adeli M. Polyglycerols. In: Parambath A, editor.Engineering of Biomaterials for Drug Delivery Systems. Elsevier; 2018:103-171. doi:10.1016/B978-0-08-101750-0.00005-2

124. Mu W, Chu Q, Liu Y, Zhang N. A review on nano-based drug delivery system for cancer chemoimmunotherapy. Nano Micro Lett. 2020;12:1-24. doi:10.1007/s40820-020-00482-6 
125. Yao Y, Zhou Y, Liu L, et al. Nanoparticle-based drug delivery in cancer therapy and its role in overcoming drug resistance. Front Mol Biosci. 2020;7. doi:10.3389/fmolb.2020.00193

126. Tu Z, Donskyi IS, Qiao H, et al. Graphene oxide-cyclic R10 peptide nuclear translocation nanoplatforms for the surmounting of multiple-drug resistance. Adv Funct Mater. 2020;30:2000933. doi:10.1002/adfm.202000933

127. Liu J, Dong J, Zhang T, Peng Q. Graphene-based nanomaterials and their potentials in advanced drug delivery and cancer therapy. J Control Release. 2018;286:64-73. doi:10.1016/j.jconrel.20 18.07.034

128. Jokar S, Pourjavadi A, Adeli M. Albumin-graphene oxide conjugates; carriers for anticancer drugs. RSC Adv. 2014;4:33001-33006. doi:10.1039/C4RA05752J

129. Viseu T, Lopes CM, Fernandes E, Real Oliveira MEC, Lúcio M. A systematic review and critical analysis of the role of graphene-based nanomaterials in cancer theranostics. Pharmaceutics. 2018;10:282. doi:10.3390/pharmaceutics10040282

130. Fusco L, Gazzi A, Peng G, et al. Graphene and other 2D materials: a multidisciplinary analysis to uncover the hidden potential as cancer theranostics. Theranostics. 2020;10:5435. doi:10.7150/ thno. 40068

131. Tu Z, Wycisk V, Cheng C, Chen W, Adeli M, Haag R. Functionalized graphene sheets for intracellular controlled release of therapeutic agents. Nanoscale. 2017;9:18931-18939. doi:10. 1039/C7NR06588D

132. Liu Z, Robinson JT, Sun X, Dai H. PEGylated nanographene oxide for delivery of water-insoluble cancer drugs. J Am Chem Soc. 2008;130:10876-10877. doi:10.1021/ja803688x

133. Chai D, Hao B, Hu R, et al. Delivery of oridonin and methotrexate via PEGylated graphene oxide. ACS Appl Mater Interfaces. 2019;11:22915-22924. doi:10.1021/acsami.9b03983

134. Demirel E, Karaca E, Durmaz YY. Effective PEGylation method to improve biocompatibility of graphene derivatives. Eur Polym J. 2020;124:109504. doi:10.1016/j.eurpolymj.2020.109504

135. Zhang Y, Liu C, Shi W, Wang Z, Dai L, Zhang X. Direct measurements of the interaction between pyrene and graphite in aqueous media by single molecule force spectroscopy: understanding the $\pi^{-} \pi$ interactions. Langmuir. 2007;23:7911-7915. doi:10.1021/la700876d

136. Zeng Y, Yang Z, Li H, et al. Multifunctional nanographene oxide for targeted gene-mediated thermochemotherapy of drug-resistant tumour. Sci Rep. 2017;7:43506. doi:10.1038/srep43506

137. Fávaro WJ, de Souza JG, Ferreira LA, et al. Hybrid graphene oxide as carrier of doxorubicin: cytotoxicity and preliminary in vivo assays against bladder cancer. Adv Nat Sci Nanosci Nanotechnol. 2020;11:025016.

138. Jiao J, Pan M, Liu X, Liu J, Li B, Chen Q. An ultrasensitive non-enzymatic sensor for quantitation of anti-cancer substance chicoric acid based on bimetallic nanoalloy with polyetherimide-capped reduced graphene oxide. Nanomaterials. 2020;10:499. doi:10.3390/nano10030499

139. Liu J, Chen X, Jiang Y, Cheng W. Development of an immune gene prognostic classifier for survival prediction and respond to immunocheckpoint inhibitor therapy/chemotherapy in endometrial cancer. Int Immunopharmacol. 2020;86:106735. doi:10.10 16/j.intimp.2020.106735

140. Soheili N, Eshghi M, Emadi-Baygi M, Mirzaei SA, Heidari R, Hosseinzadeh M. Design and evaluation of biological gate circuits and their therapeutic applications in a model of multidrug resistant cancers. Biotechnol Lett. 2020:1-11.

141. Xie B, Yi J, Peng J, et al. Characterization of synergistic anti-tumor effects of doxorubicin and p53 via graphene oxide-polyethyleneimine nanocarriers. J Mater Sci Technol. 2017;33:807-814. doi:10.1016/j.jmst.2017.05.005
142. Pooresmaeil M, Namazi H. $\beta$-Cyclodextrin grafted magnetic graphene oxide applicable as cancer drug delivery agent: synthesis and characterization. Mater Chem Phys. 2018;218:62-69. doi:10.1016/j.matchemphys.2018.07.022

143. Kalkhoran AHZ, Naghib SM, Vahidi O, Rahmanian M. Synthesis and characterization of graphene-grafted gelatin nanocomposite hydrogels as emerging drug delivery systems. Biomed Phys Eng Express. 2018;4:055017. doi:10.1088/2057-1976/aad745

144. Ma N, Liu J, He W, et al. Folic acid-grafted bovine serum albumin decorated graphene oxide: an efficient drug carrier for targeted cancer therapy. J Colloid Interface Sci. 2017;490: 598-607. doi:10.1016/j.jcis.2016.11.097

145. Wan Y, Lin Z, Zhang Q, et al. Incorporating graphene oxide into biomimetic nano-microfibrous cellulose scaffolds for enhanced breast cancer cell behavior. Cellulose. 2020:1-15.

146. Khoshoei A, Ghasemy E, Poustchi F, Shahbazi M-A, Maleki R. Engineering the $\mathrm{pH}$-sensitivity of the graphene and carbon nanotube based nanomedicines in smart cancer therapy by grafting trimetyl Chitosan. Pharm Res. 2020;37:1-13. doi:10.1007/ s11095-020-02881-1

147. Abbasian M, Roudi -M-M, Mahmoodzadeh F, Eskandani M, Jaymand M. Chitosan-grafted-poly (methacrylic acid)/graphene oxide nanocomposite as a $\mathrm{pH}$-responsive de novo cancer chemotherapy nanosystem. Int $J$ Biol Macromol. 2018;118:1871-1879. doi:10.1016/j.ijbiomac.2018.07.036

148. Gooneh-Farahani S, Naghib SM, Naimi-Jamal MR. A critical comparison study on the $\mathrm{pH}$-sensitive nanocomposites based on graphene-grafted chitosan for cancer theragnosis. Multidiscip Cancer Invest. 2019;3:5-16. doi:10.30699/acadpub.mci.3.1.5

149. Dhanavel S, Revathy T, Sivaranjani T, et al. 5-Fluorouracil and curcumin co-encapsulated chitosan/reduced graphene oxide nanocomposites against human colon cancer cell lines. Polym Bull. 2020;77:213-233. doi:10.1007/s00289-019-02734-x

150. Zhao X, Wei Z, Zhao Z, et al. Design and development of graphene oxide nanoparticle/chitosan hybrids showing $\mathrm{pH}$-sensitive surface charge-reversible ability for efficient intracellular doxorubicin delivery. ACS Appl Mater Interfaces. 2018;10:6608-6617. doi:10.1021/acsami.7b16910

151. Yang H, Bremner DH, Tao L, Li H, Hu J, Zhu L. Carboxymethyl chitosan-mediated synthesis of hyaluronic acid-targeted graphene oxide for cancer drug delivery. Carbohydr Polym. 2016;135:72-78. doi:10.1016/j.carbpol.2015.08.058

152. Xie M, Zhang F, Liu L, et al. Surface modification of graphene oxide nanosheets by protamine sulfate/sodium alginate for anti-cancer drug delivery application. Appl Surf Sci. 2018;440:853-860. doi:10.1016/j.apsusc.2018.01.175

153. Sattari S, Tehrani AD, Adeli M, Soleimani K, Rashidipour M. Fabrication of new generation of co-delivery systems based on graphene-g-cyclodextrin/chitosan nanofiber. Int $J$ Biol Macromol. 2020;156:1126-1134. doi:10.1016/j.ijbiomac.2019. 11.144

154. Wang C, Li B, Niu W, et al. $\beta$-Cyclodextrin modified graphene oxide-magnetic nanocomposite for targeted delivery and $\mathrm{pH}$-sensitive release of stereoisomeric anti-cancer drugs. RSC $A d v$. 2015;5:89299-89308. doi:10.1039/C5RA13082D

155. Xie $\mathrm{M}$, Zhang F, Peng $\mathrm{H}$, et al. Layer-by-layer modification of magnetic graphene oxide by chitosan and sodium alginate with enhanced dispersibility for targeted drug delivery and photothermal therapy. Colloids Surf B Biointerfaces. 2019;176:462-470. doi:10.1016/j.colsurfb.2019.01.028

156. Zhang F, Xie M, Zhao Y, et al. Chitosan and dextran stabilized GO-iron oxide nanosheets with high dispersibility for chemotherapy and photothermal ablation. Ceram Int. 2019;45:5996-6003. doi:10.1016/j.ceramint.2018.12.070 
157. Xie M, Lei H, Zhang Y, et al. Non-covalent modification of graphene oxide nanocomposites with chitosan/dextran and its application in drug delivery. RSC $A d v$. 2016;6:9328-9337. doi:10.1039/C5RA23823D

158. Samadi S, Moradkhani M, Beheshti H, Irani M, Aliabadi M. Fabrication of chitosan/poly (lactic acid)/graphene oxide/TiO2 composite nanofibrous scaffolds for sustained delivery of doxorubicin and treatment of lung cancer. Int $J$ Biol Macromol. 2018;110:416-424. doi:10.1016/j. ijbiomac.2017.08.048

159. Lei H, Xie M, Zhao Y, Zhang F, Xu Y, Xie J. Chitosan/sodium alginate modificated graphene oxide-based nanocomposite as a carrier for drug delivery. Ceram Int. 2016;42:17798-17805. doi:10.1016/j.ceramint.2016.08.108

160. Guo Y, Xu H, Li Y, et al. Hyaluronic acid and Arg-Gly-Asp peptide modified graphene oxide with dual receptor-targeting function for cancer therapy. J Biomater Appl. 2017;32:54-65. doi:10.1177/0885328217712110

161. Yin T, Liu J, Zhao Z, et al. Redox sensitive hyaluronic aciddecorated graphene oxide for photothermally controlled tumorcytoplasm-selective rapid drug delivery. Adv Funct Mater. 2017;27:1604620. doi:10.1002/adfm.201604620

162. Kim JH, Moon MJ, Kim DY, Heo SH, Jeong YY. Hyaluronic acid-based nanomaterials for cancer therapy. Polymers. 2018;10:1133. doi:10.3390/polym10101133

163. Kim K, Choi H, Choi ES, Park M-H, Ryu J-H. Hyaluronic acid-coated nanomedicine for targeted cancer therapy. Pharmaceutics. 2019;11:301. doi:10.3390/pharmaceutics11070 301

164. Wickens JM, Alsaab HO, Kesharwani P, et al. Recent advances in hyaluronic acid-decorated nanocarriers for targeted cancer therapy. Drug Discov Today. 2017;22:665-680. doi:10.1016/j. drudis.2016.12.009

165. Tan KH, Sattari S, Donskyi IS, et al. Functionalized 2D nanomaterials with switchable binding to investigate graphene-bacteria interactions. Nanoscale. 2018;10:9525-9537. doi:10.1039/ C8NR01347K

166. Tu Z, Achazi K, Schulz A, et al. Combination of surface charge and size controls the cellular uptake of functionalized graphene sheets. Adv Funct Mater. 2017;27:1701837. doi:10.1002/ adfm.201701837

167. Movahedi S, Adeli M, Fard AK, Maleki M, Sadeghizadeh M, Bani F. Edge-functionalization of graphene by polyglycerol; A way to change its flat topology. Polymer. 2013;54:2917-2925. doi:10.1016/j.polymer.2013.04.014

168. Sun X, Liu Z, Welsher K, et al. Nano-graphene oxide for cellular imaging and drug delivery. Nano Res. 2008;1:203-212. doi:10.1007/s12274-008-8021-8

169. Hussien NA, Işıklan N, Türk M. Aptamer-functionalized magnetic graphene oxide nanocarrier for targeted drug delivery of paclitaxel. Mater Chem Phys. 2018;211:479-488. doi:10.1016/j. matchemphys.2018.03.015

170. Oz Y, Barras A, Sanyal R, Boukherroub R, Szunerits S, Sanyal A. Functionalization of reduced graphene oxide via thiol-maleimide "click" chemistry: facile fabrication of targeted drug delivery vehicles. ACS Appl Mater Interfaces. 2017;9:34194-34203. doi:10.1021/acsami.7b08433

171. Masoudipour E, Kashanian S, Maleki N. A targeted drug delivery system based on dopamine functionalized nano graphene oxide. Chem Phys Lett. 2017;668:56-63. doi:10.1016/j.cplett.2016. 12.019

172. Song -M-M, Xu H-L, Liang J-X, Xiang -H-H, Liu R, Shen Y-X. Lactoferrin modified graphene oxide iron oxide nanocomposite for glioma-targeted drug delivery. Mater Sci Eng C. 2017;77:904-911. doi:10.1016/j.msec.2017.03.309
173. Mauro N, Scialabba C, Agnello S, Cavallaro G, Giammona G. Folic acid-functionalized graphene oxide nanosheets via plasma etching as a platform to combine NIR anticancer phototherapy and targeted drug delivery. Mater Sci Eng C. 2020;107:110201. doi:10.1016/j.msec.20 19.110201

174. Wang F, Xiao J, Chen S, et al. Polymer vesicles: modular platforms for cancer theranostics. Adv Mater. 2018;30:1705674. doi:10.1002/adma.201705674

175. Gu Z, Zhu S, Yan L, Zhao F, Zhao Y. Graphene-based smart platforms for combined Cancer therapy. Adv Mater. 2019;31:1800662. doi:10.1002/adma.201800662

176. Ye M, Zhang Z, Zhao Y, Qu L. Graphene platforms for smart energy generation and storage. Joule. 2018;2:245-268. doi:10.1016/j.joule.2017.11.011

177. Yang K, Feng L, Liu Z. Stimuli responsive drug delivery systems based on nano-graphene for cancer therapy. Adv Drug Deliv Rev. 2016;105:228-241. doi:10.1016/j.addr.2016.05.015

178. Yu X, Cheng H, Zhang M, Zhao Y, Qu L, Shi G. Graphene-based smart materials. Nat Rev Mater. 2017;2:1-13. doi:10.1038/ natrevmats.2017.46

179. Sattari S, Dadkhah Tehrani A, Adeli M. pH-responsive hybrid hydrogels as antibacterial and drug delivery systems. Polymers. 2018;10:660. doi:10.3390/polym10060660

180. He X, Li J, An S, Jiang C. pH-sensitive drug-delivery systems for tumor targeting. Ther Deliv. 2013;4:1499-1510. doi:10.4155/ tde. 13.120

181. Kavitha T, Abdi SIH, Park S-Y. pH-sensitive nanocargo based on smart polymer functionalized graphene oxide for site-specific drug delivery. Phys Chem Chem Phys. 2013;15:5176-5185. doi: $10.1039 / \mathrm{c} 3 \mathrm{cp} 00008 \mathrm{~g}$

182. Liu J, Huang Y, Kumar A, et al. pH-sensitive nano-systems for drug delivery in cancer therapy. Biotechnol Adv. 2014; 32:693-710. doi:10.1016/j.biotechadv.2013.11.009

183. Li L, Sun W, Zhong J, et al. Multistage nanovehicle delivery system based on stepwise size reduction and charge reversal for programmed nuclear targeting of systemically administered anticancer drugs. Adv Funct Mater. 2015;25:4101-4113. doi:10.1002/ adfm. 201501248

184. Han SS, Li ZY, Zhu JY, et al. Dual-pH sensitive charge-reversal polypeptide micelles for tumor-triggered targeting uptake and nuclear drug delivery. Small. 2015;11:2543-2554. doi:10.1002/ smll.201402865

185. Zhou Z, Shen Y, Tang J, et al. Charge-reversal drug conjugate for targeted cancer cell nuclear drug delivery. Adv Funct Mater. 2009;19:3580-3589. doi:10.1002/adfm.20090 0825

186. Ballatori N, Krance SM, Notenboom S, Shi S, Tieu K, Hammond CL. Glutathione dysregulation and the etiology and progression of human diseases. Biol Chem. 2009;390:191-214. doi:10.1515/BC.2009.033

187. Dringen R. Metabolism and functions of glutathione in brain. Prog Neurobiol. 2000;62:649-671.

188. Ma N, Song A, Li Z, Luan Y. Redox-sensitive prodrug molecules meet graphene oxide: an efficient graphene oxide-based nanovehicle toward cancer therapy. ACS Biomater Sci Eng. 2019;5:1384-1391. doi:10.1021/acsbiomaterials.9b00114

189. Yao J, Feng J, Chen J. External-stimuli responsive systems for cancer theranostic. Asian J Pharm Sci. 2016;11:585-595. doi:10.1016/j.ajps.2016.06.001

190. Moradi M. Design and Evaluation of a GUI for Signal and Data Analysis of Mobile Functional Near-Infrared Spectroscopy Systems. Wichita State University; 2020.

191. Yang H, Zhang Y, Chen S, Hao R. Micro-optical components for bioimaging on tissues, cells and subcellular structures. Micromachines. 2019;10:405. doi:10.3390/mi10060405 
192. Sreejith S, Huong TTM, Borah P, Zhao Y. Organic-inorganic nanohybrids for fluorescence, photoacoustic and Raman bioimaging. Sci Bull. 2015;60:665-678. doi:10.1007/s11434-0150765-4

193. Pei Y, Wei M-Y. Newly-engineered materials for bio-imaging technology: a focus on the hybrid system of ultrasound and fluorescence. Front Bioeng Biotechnol. 2019;7:88. doi:10.3389/ fbioe. 2019.00088

194. Han Z, Porter AE. In situ electron microscopy of complex biological and nanoscale systems: challenges and opportunities. Front Nanotechnol. 2020;2:20. doi:10.3389/fnano.2020.606253

195. Zhu X, Liu Y, Li P, Nie Z, Li J. Applications of graphene and its derivatives in intracellular biosensing and bioimaging. Analyst. 2016;141:4541-4553. doi:10.1039/C6AN01090C

196. Godin AG, Setaro A, Gandil M, et al. Photoswitchable single-walled carbon nanotubes for super-resolution microscopy in the near-infrared. Sci $A d v$. 2019;5:eaax1166. doi:10.1126/ sciadv.aax 1166

197. Gao X, Cheng L, Jiang W, Li X-K, Xing F. Graphene and its derivatives-based optical sensors. Front Chem. 2021;9:5. doi:10.3389/fchem.2021.615164

198. Tomita S, Ishihara S, Kurita R. A multi-fluorescent DNA/graphene oxide conjugate sensor for signature-based protein discrimination. Sensors. 2017;17:2194. doi:10.3390/s17102194

199. Nurunnabi M, Khatun Z, Reeck GR, Lee DY, Lee Y-K. Photoluminescent graphene nanoparticles for cancer phototherapy and imaging. ACS Appl Mater Interfaces. 2014;6:12413-12421. doi:10.1021/am504071z

200. Zheng P, Wu N. Fluorescence and sensing applications of graphene oxide and graphene quantum dots: a review. Chem Asian J. 2017;12:2343-2353. doi:10.1002/asia.201700814

201. Treossi E, Melucci M, Liscio A, Gazzano M, Samorì P, Palermo V. High-contrast visualization of graphene oxide on dye-sensitized glass, quartz, and silicon by fluorescence quenching. J Am Chem Soc. 2009;131:15576-15577. doi:10.10 21/ja9055382

202. Wang Y, Kurunthu D, Scott GW, Bardeen CJ. Fluorescence quenching in conjugated polymers blended with reduced graphitic oxide. J Phys Chem C. 2010;114:4153-4159. doi:10.1021/ jp9097793

203. Alava T, Mann JA, Théodore C, et al. Control of the grapheneprotein interface is required to preserve adsorbed protein function. Anal Chem. 2013;85:2754-2759. doi:10.1021/ac303268z

204. Gollavelli G, Ling Y-C. Multi-functional graphene as an in vitro and in vivo imaging probe. Biomaterials. 2012;33:2532-2545. doi:10.1016/j.biomaterials.2011.12.010

205. Younis MR, He G, Lin J, Huang P. Recent advances on graphene quantum dots for bioimaging applications. Front Chem. 2020;8. doi:10.3389/fchem.2020.00424

206. Bellet P, Gasparotto M, Pressi S, et al. Graphene-based scaffolds for regenerative medicine. Nanomaterials. 2021;11:404. doi:10.3390/nano11020404

207. Liu Z, Guo Z, Zhong H, Qin X, Wan M, Yang B. Graphene oxide based surface-enhanced Raman scattering probes for cancer cell imaging. Phys Chem Chem Phys. 2013;15:2961-2966. doi:10.1039/c2cp43715e

208. Dong H, Dai W, Ju H, et al. Multifunctional poly (1-lactide)polyethylene glycol-grafted graphene quantum dots for intracellular microRNA imaging and combined specific-gene-targeting agents delivery for improved therapeutics. ACS Appl Mater Interfaces. 2015;7:11015-11023. doi:10.1021/acsami. $5 \mathrm{~b} 02803$

209. de Melo-diogo D, Lima-Sousa R, Alves CG, Correia IJ. Graphene family nanomaterials for application in cancer combination photothermal therapy. Biomater Sci. 2019;7:3534-3551. doi:10.1039/C9BM00577C
210. Palmieri V, Spirito MD, Papi M. Graphene-based scaffolds for tissue engineering and photothermal therapy. Nanomedicine. 2020;15:1411-1417. doi:10.2217/nnm-2020-0050

211. Li Z, Lei H, Kan A, Xie H, Yu W. Photothermal applications based on graphene and its derivatives: a state-of-the-art review. Energy. 2020:119262.

212. Chen Y-W, Su Y-L, Hu S-H, Chen S-Y. Functionalized graphene nanocomposites for enhancing photothermal therapy in tumor treatment. Adv Drug Deliv Rev. 2016;105:190-204. doi:10.1016/ j.addr.2016.05.022

213. Guday G, Nickl P, Adeli M, Haag R. Reversible photothermal homogenization of fluorous biphasic systems with perfluoroalkylated nanographene. ACS Appl Nano Mater. 2020;3:1139-1146. doi:10.1021/acsanm.9b01611

214. Bani F, Adeli M, Movahedi S, Sadeghizadeh M. Graphene-polyglycerol-curcumin hybrid as a near-infrared (NIR) laser stimuliresponsive system for chemo-photothermal cancer therapy. RSC Adv. 2016;6:61141-61149. doi:10.1039/C6RA05917A

215. Cheon YA, Bae JH, Chung BG. Reduced graphene oxide nanosheet for chemo-photothermal therapy. Langmuir. 2016;32:2731-2736. doi:10.1021/acs.langmuir.6b00315

216. Wang Y, Zhang H, Xie J, Liu Y, Wang S, Zhao Q. Three dimensional mesoporous carbon nanospheres as carriers for chemo-photothermal therapy compared with two dimensional graphene oxide nanosheets. Colloids Surf A Physicochem Eng Asp. 2020;590:124498. doi:10.1016/j.colsurfa.2020.124498

217. Jun SW, Manivasagan P, Kwon J, et al. Folic acid-conjugated chitosan-functionalized graphene oxide for highly efficient photoacoustic imaging-guided tumor-targeted photothermal therapy. Int $J$ Biol Macromol. 2020;155:961-971. doi:10.1016/j. ijbiomac.2019.11.055

218. Wang L, Wang M, Zhou B, et al. PEGylated reduced-graphene oxide hybridized with $\mathrm{Fe} 3 \mathrm{O} 4$ nanoparticles for cancer photothermal-immunotherapy. J Mater Chem B. 2019;7:74 06-7414. doi:10.1039/C9TB00630C

219. Lu D, Tao R, Wang Z. Carbon-based materials for photodynamic therapy: a mini-review. Front Chem Sci Eng. 2019;13:310-323. doi:10.1007/s11705-018-1750-7

220. Rizwan M, Rasheed T, Raza A, et al. Photodynamic-based therapeutic modalities to fight against cancer-A review from synergistic viewpoint. J Drug Deliv Sci Technol. 2019;51:70-82. doi:10.1016/j.jddst.2019.02.014

221. Hu Z, Wang C, Zhao F, et al. Fabrication of a graphene/C 60 nanohybrid via $\gamma$-cyclodextrin host-guest chemistry for photodynamic and photothermal therapy. Nanoscale. 2017;9:8825-8833. doi:10.1039/C7NR02922E

222. Liu J, Liu K, Feng L, Liu Z, Xu L. Comparison of nanomedicine-based chemotherapy, photodynamic therapy and photothermal therapy using reduced graphene oxide for the model system. Biomater Sci. 2017;5:331-340. doi:10.1039/ C6BM00526H

223. Sun X, Zebibula A, Dong X, et al. Aggregation-induced emission nanoparticles encapsulated with PEGylated nano graphene oxide and their applications in two-photon fluorescence bioimaging and photodynamic therapy in vitro and in vivo. ACS Appl Mater Interfaces. 2018;10:25037-25046. doi:10.1021/ acsami.8b05546

224. Huang X, Chen J, Wu W, et al. Delivery of MutT homolog 1 inhibitor by functionalized graphene oxide nanoparticles for enhanced chemo-photodynamic therapy triggers cell death in osteosarcoma. Acta Biomater. 2020;109:229-243. doi:10.1016/j. actbio.2020.04.009

225. Ahirwar S, Mallick S, Bahadur D. Photodynamic therapy using graphene quantum dot derivatives. $J$ Solid State Chem. 2020;282:121107. doi:10.1016/j.jssc.2019.121107 
226. Goswami R, Subramanian G, Silayeva L, et al. Gene therapy leaves a vicious cycle. Front Oncol. 2019;9:297. doi:10.3389/ fonc. 2019.00297

227. Kamimura K, Suda T, Zhang G, Liu D. Advances in gene delivery systems. Pharmaceut Med. 2011;25:293-306. doi:10.1007/ BF03256872

228. Ramamoorth M, Narvekar A. Non viral vectors in gene therapy-an overview. J Clin Diag Res. 2015;9:GE01. doi:10.7860/JCDR/2015/10443.5394

229. Mogler MA, Kamrud KI. RNA-based viral vectors. Expert Rev Vaccines. 2015;14:283-312.

230. Hemminki O, Hemminki A. A century of oncolysis evolves into oncolytic immunotherapy. Oncoimmunology. 2016;5:e1074377. doi:10.1080/2162402X.2015.1074377

231. Ledford H. Cancer-fighting viruses win approval. Nat News. 2015;526:622. doi:10.1038/526622a

232. Kang Z, Meng Q, Liu K. Peptide-based gene delivery vectors. J Mater Chem B. 2019;7:1824-1841.

233. Dehshahri A, Sadeghpour H, Oskuee RK, et al. Interleukin-12 plasmid DNA delivery using 1-thyroxine-conjugated polyethylenimine nanocarriers. $J$ Nanoparticle Res. 2014;16:1-14. doi:10.1007/s11051-014-2423-1

234. Bono N, Ponti F, Mantovani D, Candiani G. Non-viral in vitro gene delivery: it is now time to set the bar! Pharmaceutics. 2020;12:183. doi:10.3390/pharmaceutics12020183

235. Meacham JM, Durvasula K, Degertekin FL, Fedorov AG. Physical methods for intracellular delivery: practical aspects from laboratory use to industrial-scale processing. J Lab Autom. 2014;19:1-18. doi:10.1177/2211068213494388

236. Liu C, Zhang L, Zhu W, et al. Barriers and strategies of cationic liposomes for cancer gene therapy. Mol Ther Methods Clin Dev. 2020;18:751-764. doi:10.1016/j.omtm.2020.07.015

237. Dharmalingam P, Rachamalla HKR, Lohchania B, et al. Green transfection: cationic lipid nanocarrier system derivatized from vegetable fat, palm stearin enhances nucleic acid transfections. ACS Omega. 2017;2:7892-7903. doi:10.1021/acsomega.7b00935

238. Taylor RE, Zahid M. Cell penetrating peptides, novel vectors for gene therapy. Pharmaceutics. 2020;12:225. doi:10.3390/ pharmaceutics 12030225

239. Zavradashvili N, Sarisozen C, Titvinidze G, et al. Library of cationic polymers composed of polyamines and arginine as gene transfection agents. ACS Omega. 2019;4:2090-2101. doi:10. 1021/acsomega.8b02977

240. Van Bruggen C, Hexum JK, Tan Z, Dalal RJ, Reineke TM. Nonviral gene delivery with cationic glycopolymers. Acc Chem Res. 2019;52:1347-1358. doi:10.1021/acs.accounts.8b00665

241. Zakeri A, Kouhbanani MAJ, Beheshtkhoo N, et al. Polyethylenimine-based nanocarriers in co-delivery of drug and gene: a developing horizon. Nano Rev Exp. 2018;9:1488497. doi:10.1080/20022727.2018.1488497

242. Jiang C, Qi Z, Jia H, et al. ATP-responsive low-molecular-weight polyethylenimine-based supramolecular assembly via host-guest interaction for gene delivery. Biomacromolecules. 2018; 20:478-489. doi:10.1021/acs.biomac.8b01395

243. Vincent M, De Lázaro I, Kostarelos K. Graphene materials as 2D non-viral gene transfer vector platforms. Gene Ther. 2017; 24:123-132. doi:10.1038/gt.2016.79

244. Gong X, Liu G, Li Y, Yu DYW, Teoh WY. Functionalizedgraphene composites: fabrication and applications in sustainable energy and environment. Chem Mater. 2016;28:8082-8118. doi:10.1021/acs.chemmater.6b01447

245. Mukherjee S, Bytesnikova Z, Ashrafi A, Adam V, Richtera L. Graphene oxide as a nanocarrier for biochemical molecules: current understanding and trends. Processes. 2020;8:1636. doi: $10.3390 /$ pr8121636
246. Mugnano M, Lama G, Castaldo R, et al. Cellular uptake of mildly oxidized nanographene for drug-delivery applications. ACS Appl Nano Mater. 2019;3:428-439. doi:10.1021/acsanm.9b02035

247. Hoseini-Ghahfarokhi M, Mirkiani S, Mozaffari N, et al. Applications of graphene and graphene oxide in smart drug/ gene delivery: is the world still flat? Int $J$ Nanomedicine. 2020;15:9469. doi:10.2147/IJN.S265876

248. Imani R, Mohabatpour F, Mostafavi F. Graphene-based nano-carrier modifications for gene delivery applications. Carbon. 2018;140:569-591. doi:10.1016/j.carbon.2018.09.019

249. Dou C, Ding N, Luo F, et al. Graphene-based microRNA transfection blocks preosteoclast fusion to increase bone formation and vascularization. Adv Sci. 2018;5:1700578. doi:10.1002/advs.201700578

250. Kim H, Namgung R, Singha K, Oh I-K, Kim WJ. Graphene oxide-polyethylenimine nanoconstruct as a gene delivery vector and bioimaging tool. Bioconjug Chem. 2011;22:2558-2567. doi:10.1021/bc200397j

251. Yin F, Hu K, Chen Y, et al. SiRNA delivery with PEGylated graphene oxide nanosheets for combined photothermal and genetherapy for pancreatic cancer. Theranostics. 2017;7:1133. doi:10.7150/thno.17841

252. Sun Y, Ye X, Cai M, et al. Osteoblast-targeting-peptide modified nanoparticle for siRNA/microRNA delivery. ACS Nano. 2016;10:5759-5768. doi:10.1021/acsnano.5b07828

253. Paul A, Hasan A, Kindi HA, et al. Injectable graphene oxide/ hydrogel-based angiogenic gene delivery system for vasculogenesis and cardiac repair. ACS Nano. 2014;8:8050-8062. doi:10. $1021 / \mathrm{nn} 5020787$

254. Zhi F, Dong H, Jia X, et al. Functionalized graphene oxide mediated adriamycin delivery and miR-21 gene silencing to overcome tumor multidrug resistance in vitro. PLoS One. 2013;8: e60034. doi:10.1371/journal.pone.0060034

255. Zhang H, Yan T, Xu S, et al. Graphene oxide-chitosan nanocomposites for intracellular delivery of immunostimulatory $\mathrm{CpG}$ oligodeoxynucleotides. Mater Sci Eng C. 2017;73:144-151. doi:10.1016/j.msec.2016.12.072

256. Dowaidar M, Abdelhamid HN, Hällbrink M, Zou X, Langel Ü. Graphene oxide nanosheets in complex with cell penetrating peptides for oligonucleotides delivery. Biochim Biophys Acta Gen Subj. 2017;1861:2334-2341. doi:10.1016/j.bbagen.2017.07.002

257. Yang M, Liu Y, Fan T, Zhang D. Metal-graphene interfaces in epitaxial and bulk systems: a review. Prog Mater Sci. 2020;110:100652.

258. Cusati T, Fiori G, Gahoi A, et al. Electrical properties of graphene-metal contacts. Sci Rep. 2017;7:1-11. doi:10.1038/ s41598-017-05069-7

259. Bai S, Shen X. Graphene-inorganic nanocomposites. RSC $A d v$. 2012;2:64-98.

260. Al-Ani LA, AlSaadi MA, Kadir FA, Hashim NM, Julkapli NM, Yehye WA. Graphene-gold based nanocomposites applications in cancer diseases; Efficient detection and therapeutic tools. Eur J Med Chem. 2017;139:349-366.

261. Assali A, Razzazan S, Akhavan O, Mottaghitalab F, Adeli M, Atyabi F. The bio-interface between functionalized Au NR@GO nanoplatforms with protein corona and their impact on delivery and release system. Colloids Surf $B$ Biointerfaces. 2019;173:891-898. doi:10.1016/j.colsurfb.2018.10.042

262. Assali A, Akhavan O, Adeli M, et al. Multifunctional core-shell nanoplatforms (gold@graphene oxide) with mediated NIR thermal therapy to promote miRNA delivery. Nanomedicine. 2018;14:1891-1903. doi:10.1016/j.nano.2018.05.016

263. Huang J, Zhang L, Chen B, et al. Nanocomposites of size-controlled gold nanoparticles and graphene oxide: formation and applications in SERS and catalysis. Nanoscale. 2010; 2:2733-2738. doi:10.1039/c0nr00473a 
264. Pham TA, Choi BC, Lim KT, Jeong YT. A simple approach for immobilization of gold nanoparticles on graphene oxide sheets by covalent bonding. Appl Surf Sci. 2011;257:3350-3357. doi:10.1016/j.apsusc.2010.11.023

265. Sangili A, Kalyani T, Chen S-M, Nanda A, Jana SK. Label-free electrochemical immunosensor based on one-step electrochemical deposition of AuNP-RGO nanocomposites for detection of endometriosis marker CA 125. ACS Applied Bio Mater. 2020;3:7620-7630. doi:10.1021/acsabm.0c00821

266. Zhang X, Li F, Wei Q, Du B, Wu D, Li H. Ultrasensitive nonenzymatic immunosensor based on bimetallic gold-silver nanoclusters synthesized by simple mortar grinding route. Sens Actuators B Chem. 2014;194:64-70. doi:10.1016/j.snb.2013.12.065

267. Chen H, Tang D, Zhang B, Liu B, Cui Y, Chen G. Electrochemical immunosensor for carcinoembryonic antigen based on nanosilver-coated magnetic beads and gold-graphene nanolabels. Talanta. 2012;91:95-102. doi:10.1016/j.talanta.2012.01.025

268. Fan Y, Shi S, Ma J, Guo Y. A paper-based electrochemical immunosensor with reduced graphene oxide/thionine/gold nanoparticles nanocomposites modification for the detection of cancer antigen 125 . Biosens Bioelectron. 2019;135:1-7. doi:10.1016/j.bios.2019.03.063

269. Ye Y, Yan W, Liu Y, et al. Electrochemical detection of Salmonella using an invA genosensor on polypyrrole-reduced graphene oxide modified glassy carbon electrode and AuNPs-horseradish peroxidase-streptavidin as nanotag. Anal Chim Acta. 2019;1074:80-88. doi:10.1016/j.aca.2019.05.012

270. Shamsipur M, Samandari L, Farzin L, Molaabasi F, Mousazadeh MH. Dual-modal label-free genosensor based on hemoglobin@ gold nanocluster stabilized graphene nanosheets for the electrochemical detection of BCR/ABL fusion gene. Talanta. 2020;217:121093. doi:10.1016/j.talanta.2020.121093

271. Mobed A, Hasanzadeh M, Shadjou N, Hassanpour S, Saadati A, Agazadeh M. Immobilization of ssDNA on the surface of silver nanoparticles-graphene quantum dots modified by gold nanoparticles towards biosensing of microorganism. Microchem $J$. 2020;152:104286. doi:10.1016/j.microc.2019.104286

272. Wang Z, Sun X, Huang T, Song J, Wang Y. A sandwich nanostructure of gold nanoparticle coated reduced graphene oxide for photoacoustic imaging-guided photothermal therapy in the second NIR window. Front Bioeng Biotechnol. 2020;8:655. doi:10.3389/fbioe.2020.00655

273. Cheng Y, Chang Y, Feng Y, et al. Simulated sunlight-mediated photodynamic therapy for melanoma skin cancer by titanium-dioxide-nanoparticle-gold-nanocluster-graphene heterogeneous nanocomposites. Small. 2017;13:1603935. doi:10.1002/smll.201603935

274. Lin C-W, Wei K-C, Liao S-S, et al. A reusable magnetic graphene oxide-modified biosensor for vascular endothelial growth factor detection in cancer diagnosis. Biosens Bioelectron. 2015;67:431-437. doi:10.1016/j.bios.2014.08.080

275. Huang Y-S, Lu Y-J, Chen J-P. Magnetic graphene oxide as a carrier for targeted delivery of chemotherapy drugs in cancer therapy. J Magn Magn Mater. 2017;427:34-40. doi:10.1016/j. jmmm.2016.10.042

276. Gonzalez-Rodriguez R, Campbell E, Naumov A. Multifunctional graphene oxide/iron oxide nanoparticles for magnetic targeted drug delivery dual magnetic resonance/fluorescence imaging and cancer sensing. PLoS One. 2019;14:e0217072. doi:10.1371/journal.pone. 0217072

277. Li Y, Dong H, Tao Q, et al. Enhancing the magnetic relaxivity of MRI contrast agents via the localized superacid microenvironment of graphene quantum dots. Biomaterials. 2020;250:120056. doi:10.1016/j.biomaterials.2020.120056

278. Meng J, Chen X, Tian Y, Li Z, Zheng Q. Nanoscale metalorganic frameworks decorated with graphene oxide for magnetic resonance imaging guided photothermal therapy. Chem Eur J. 2017;23:17521-17530. doi:10.1002/chem.201702573
279. Liu H, Li C, Qian Y, et al. Magnetic-induced graphene quantum dots for imaging-guided photothermal therapy in the second near-infrared window. Biomaterials. 2020;232:119700. doi:10.1016/j.biomaterials.2019.119700

280. Han S, Teng F, Wang Y, Su L, Leng Q, Jiang H. Drug-loaded dual targeting graphene oxide-based molecularly imprinted composite and recognition of carcino-embryonic antigen. RSC $A d v$. 2020;10:10980-10988. doi:10.1039/D0RA00574F

281. Liang W, Huang Y, Lu D, et al. $\beta$-cyclodextrin-hyaluronic acid polymer functionalized magnetic graphene oxide nanocomposites for targeted photo-chemotherapy of tumor cells. Polymers. 2019;11:133. doi:10.3390/polym11010133

282. Hatamie S, Shih P-J, Zomorod MS, Heravi P, Ahadian MM, Hatami N. Hyperthermia response of PEGylated magnetic graphene nanocomposites for heating applications and accelerate antibacterial activity using magnetic fluid hyperthermia. Appl Phys A. 2020;126:1-10. doi:10.1007/s00339-020-3454-3

283. Yao X, Niu X, Ma K, et al. Graphene quantum dots-capped magnetic mesoporous silica nanoparticles as a multifunctional platform for controlled drug delivery, magnetic hyperthermia, and photothermal therapy. Small. 2017;13:1602225. doi:10.1002/ smll.201602225

284. Wang $\mathrm{H}$, Revia R, Wang $\mathrm{K}$, et al. Paramagnetic properties of metal-free boron-doped graphene quantum dots and their application for safe magnetic resonance imaging. Adv Mater. 2017;29:1605416. doi:10.1002/adma.201605416

285. Kooti M, Sedeh AN, Motamedi H, Rezatofighi SE. Magnetic graphene oxide inlaid with silver nanoparticles as antibacterial and drug delivery composite. Appl Microbiol Biotechnol. 2018;102:3607-3621. doi:10.1007/s00253-018-8880-1

286. Chen H, Qiu Y, Ding D, et al. Gadolinium-encapsulated graphene carbon nanotheranostics for imaging-guided photodynamic therapy. Adv Mater. 2018;30:1802748. doi:10.1002/adma.201802748

287. Chawda N, Basu M, Majumdar D, Poddar R, Mahapatra SK, Banerjee I. Engineering of gadolinium-decorated graphene oxide nanosheets for multimodal bioimaging and drug delivery. ACS Omega. 2019;4:12470-12479. doi:10.1021/acsomega.9b00883

288. Zeng Y, Li H, Li Z, et al. Engineered gadolinium-based nanomaterials as cancer imaging agents. Appl Mater Today. 2020;20:100686

289. Lee BH, Hasan MT, Lichthardt D, Gonzalez-Rodriguez R, Naumov AV. Manganese-nitrogen and gadolinium-nitrogen Codoped graphene quantum dots as bimodal magnetic resonance and fluorescence imaging nanoprobes. Nanotechnology. 2020;32:095103. doi:10.1088/1361-6528/abc642

290. Usman MS, Hussein MZ, Kura AU, Fakurazi S, Masarudin MJ, Ahmad Saad FF. Graphene oxide as a nanocarrier for a theranostics delivery system of protocatechuic acid and gadolinium/gold nanoparticles. Molecules. 2018;23:500. doi:10.3390/ molecules 23020500

291. Thapa RK, Soe ZC, Ou W, et al. Palladium nanoparticle-decorated 2-D graphene oxide for effective photodynamic and photothermal therapy of prostate solid tumors. Colloids Surf B Biointerfaces. 2018;169:429-437. doi:10.1016/j. colsurfb.2018.05.051

292. Ruiyi L, Tinling P, Hongxia C, Jinsong S, Zaijun L. Electrochemical detection of cancer cells in human blood using folic acid and glutamic acid-functionalized graphene quantum dot-palladium@gold as redox probe with excellent electrocatalytic activity and target recognition. Sens Actuators B Chem. 2020;309:127709. doi:10.1016/j.snb.2020.127709 


\section{Publish your work in this journal}

The International Journal of Nanomedicine is an international, peerreviewed journal focusing on the application of nanotechnology in diagnostics, therapeutics, and drug delivery systems throughout the biomedical field. This journal is indexed on PubMed Central, MedLine, CAS, SciSearch ${ }^{\circledR}$, Current Contents ${ }^{\circledR} /$ Clinical Medicine, $^{\circ}$
Journal Citation Reports/Science Edition, EMBase, Scopus and the Elsevier Bibliographic databases. The manuscript management system is completely online and includes a very quick and fair peer-review system, which is all easy to use. Visit http://www.dovepress.com/ testimonials.php to read real quotes from published authors.

Submit your manuscript here: https://www.dovepress.com/international-journal-of-nanomedicine-journal 